UNIVERSIDADE DE SÃO PAULO

FACULDADE DE DIREITO DE RIBEIRÃO PRETO

PEDRO AURÉLIO DE QUEIROZ PEREIRA DA SILVA

Concorrência e desenvolvimento: a competition advocacy no Brasil e sua contribuição para o fortalecimento das instituições democráticas 


\title{
Concorrência e desenvolvimento: a competition advocacy no Brasil e sua contribuição para o fortalecimento das instituições democráticas
}

\begin{abstract}
Dissertação apresentada ao Programa de Pós-Graduação em Direito da Faculdade de Direito de Ribeirão Preto da Universidade de São Paulo como requisito para a obtenção do título de Mestre em Ciências.

Área de Concentração: Desenvolvimento no Estado Democrático de Direito.

Orientadora: Prof. $^{\text {a }}$ Doutora Juliana Oliveira Domingues.
\end{abstract}

\section{Versão corrigida}

Ribeirão Preto 
Autorizo a reprodução e divulgação total ou parcial deste trabalho, por qualquer meio convencional ou eletrônico, para fins de estudo e pesquisa, desde que citada a fonte.

Ficha catalográfica elaborada pela Biblioteca

e Seção Técnica de Informática da FDRP/USP, com os dados fornecidos pelo(a) autor(a)

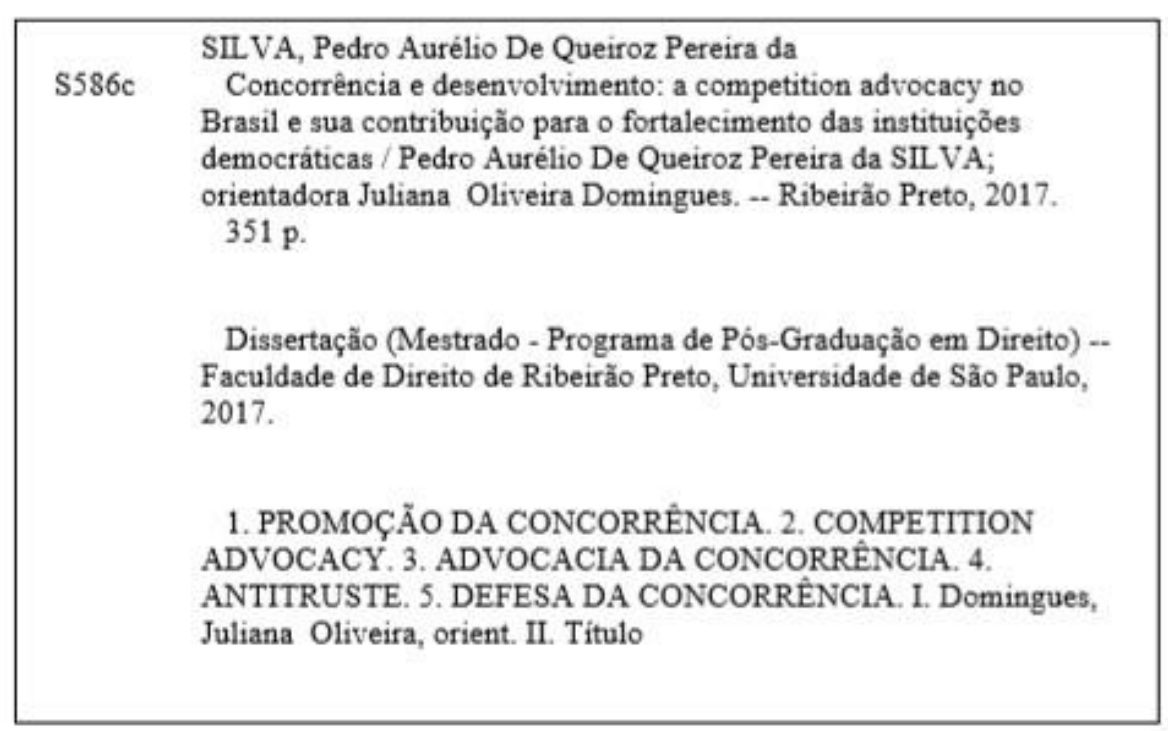




\section{FOLHA DE APROVAÇÃO}

Nome: SILVA, Pedro Aurélio de Queiroz Pereira da.

Título: Concorrência e desenvolvimento: a Competition Advocacy no Brasil e sua contribuição para o fortalecimento das instituições democráticas

Dissertação de Mestrado apresentada ao Programa de Pós-Graduação em Direito da Faculdade de Direito de Ribeirão Preto da Universidade de São Paulo para obtenção do título de Mestre em Ciências - Área de Concentração: Desenvolvimento no Estado Democrático de Direito.

Aprovado em:

Banca Examinadora

Prof. Dr.

Instituição:

Julgamento:

Assinatura:

Prof. Dr.

Instituição:

Julgamento:

Assinatura:

Prof. Dr.

Instituição:

Julgamento: Assinatura: 
DEDICATÓRIA

À Divina Hierarquia 


\section{AGRADECIMENTOS}

Como na conhecida lenda de Jonas em que este, afastando-se de Nínive, ${ }^{1}$ tentara fugir a Társis, mas fora "tragado" por uma baleia que o devolveu àquele que seria seu real destino, o tema desta pesquisa possui, em alguma medida, uma ligação com a trajetória deste subscritor. Ainda em 2002, quando no exercício da função de Coordenador-Geral da extinta SDE /MJ, por ocasião de discussões sobre uma recém-apresentada proposta de Guia de Análise de Preços Predatórios da SEAE/MF, debatíamos, informalmente, sobre a necessidade de ampliar a atuação na matéria antitruste, até em razão de uma embrionária percepção quanto à insuficiência de mecanismos satisfatórios para efetivação da livre concorrência. Naquela mesma ocasião, a SDE havia sido oficiada pelo CADE, mais especificamente, pelo ex-Conselheiro e Professor Ronaldo Porto Macedo Jr. para se manifestar sobre complexo tema envolvendo questões relativas a tarifas de interconexão entre operadoras de telefonia. O tema de fundo que motivou o ofício não vem ao caso, mas a verdade é que se tratava de expediente pouco usual, já que a SDE, raramente, seria oficiada pelo CADE para se manifestar sobre questões do gênero (era a SDE que, normalmente, instruía os processos que iriam para o CADE e aquele era um expediente excepcional, uma demanda imprevista). Além de uma certa novidade na discussão da matéria regulatória pelo SBDC, o caso provocou certo alvoroço, pois, até então, órgãos do sistema não estavam acostumados com questões que envolveriam a configuração concorrencial de setores, nomeadamente, em razão da rotineira e habitual atuação adjudicatória no controle de atos de concentração e na repressão de ilícitos concorrenciais. Com efeito, a compreensão geral de "advocacia da concorrência" se restringia a uma noção bastante vaga e abrangente de difusão da cultura concorrencial (a famosa "função educativa"). Não alcançava questões mais difíceis como a relatada acima. Ainda naquele ano, influenciados talvez pelas autoridades do DOJ e da extinta OFT presentes no IV Workshop Internacional de Cartéis realizado no Rio de Janeiro, iniciávamos também discussões de temas como compliance e fraudes concorrenciais em licitação, grandes novidades até então no antitruste.

Eis que, nos últimos anos, o tema da "advocacia da concorrência" volta à baila e me deparo com o enorme desafio de "retornar a Nínive" e, despretensiosamente, tentar contribuir para a edificação de uma teoria geral da promoção da concorrência ou algo que o valha.

\footnotetext{
${ }^{1}$ Nínive corresponderia hoje a cidade iraquiana de Mossul.
} 
Nesse contexto, seria injusto direcionar meus agradecimentos para uma ou outra pessoa especial, pois foram muitos aqueles que auxiliaram e "coparticiparam" dos sacrifícios para conclusão desta empreitada que, certamente, se iniciou muito antes do ingresso neste Programa. Assim, gostaria de registrar meus agradecimentos aos Professores das disciplinas que influenciaram, decisivamente, no conteúdo desta dissertação: a minha orientadora, Professora Juliana Domingues (Grupos Econômicos); os Professores Vinícius Marques Carvalho e Marcos Paulo Veríssimo (Corrupção e Concorrência); o Professor Sérgio Nojiri (Teorias da Justiça); a Professora Fabiana Severi (Metodologia); o Professor Gustavo Assed (Direito e Desenvolvimento); os Professores Thiago Marrara e Raul de Oliveira (Administração Pública e Desenvolvimento). Gostaria de agradecer o carinho das Professoras do PAE, Professora Cristina Godoy e Professora Maria Paula Bertran Muñoz que me auxiliaram, criticamente, no projeto de pesquisa. Não poderia, entretanto, deixar de agradecer a Professora Cristiane Derani com quem, ainda como aluno especial na disciplina de Direito Ambiental Econômico no Programa de Pós-Graduação do Largo do São Francisco em 2004, pude aprender conceitos fundamentais que seriam caros para esta dissertação.

Meus agradecimentos ao Professor Carlos Ragazzo que, assim como o Prof. Vinícius Carvalho, foram meus colegas da Turma X de Especialista em Políticas Públicas e Gestão Governamental na Escola Nacional de Administração Pública em Brasília e que me auxiliou no envio de texto que, de outra forma, seria de difícil acesso. Agradeço ao Professor Leonardo Arquimino de Carvalho que também me auxiliou no envio de sua extraordinária pesquisa sobre o ensino do direito da concorrência no Brasil (triste conclusão!) e que foi, sem dúvida, importantíssima para o desenvolvimento deste trabalho. Meus sinceros agradecimentos à Professora Noeli Rivas da Faculdade de Filosofia, Ciências e Letras de Ribeirão Preto (Docência) pelo valoroso auxílio sobre a temática curricular, particularmente, útil para o último capítulo. Por fim, agradeço a minha querida amiga Aline Lemos Reis Bianchini pela revisão formal do texto.

Ditas estas palavras, permito-me compartilhar o mérito do trabalho com todos aqueles que me auxiliaram nesta trajetória com o desejo de que este esforço investigativo possa contribuir, em alguma medida, para o desenvolvimento social e econômico, para a democratização das instituições e, principalmente, para melhoria das condições de vida da sociedade. 
Se existe a ideia de uma sabedoria que tu podes ver e que eи o saiba, e que eи posso ver sem que tu o saibas, e que por isso não podemos mostrar um ao outro, e, contudo, é idêntica em todos, é mister admitir que tal ideia nos seja igualmente acessível a todos Santo Agostinho (De lib. arb., II, 10, 28).

Quando teu entendimento transcender a ignorância da separatividade, então obterás a revelação de todo o ensinamento, seja do conhecido, ou daquele por conhecer Srimad Bhagavad Gita (1990:109) 


\section{RESUMO}

SILVA, Pedro Aurélio de Queiroz Pereira da. Concorrência e desenvolvimento: a Competition Advocacy no Brasil e sua contribuição para o fortalecimento das instituições democráticas. 2017. 326 f. Dissertação (Mestrado) - Faculdade de Direito de Ribeirão Preto, Universidade de São Paulo, Ribeirão Preto, 2017.

A presente pesquisa buscou avaliar se o direito da concorrência, tal como edificado no presente, tem-se revelado suficiente para alcançar o fenômeno concorrencial de modo efetivo e, portanto, se estaria, de fato, a realizar sua missão no sentido de contribuir para o desenvolvimento e para a democracia. Objetivou-se demonstrar que os mecanismos convencionais de defesa da concorrência (controle de condutas e de atos de concentração) seriam incapazes de fazer frente à crescente concentração dos mercados e à eliminação ou mesmo redução de distorções competitivas ocasionadas, ainda que indiretamente, pelo próprio Estado. Demonstrou-se que estes problemas estariam a impactar a própria ideia de democracia e colocariam em risco o desenvolvimento econômico e social. A partir do referencial teórico utilizado, procurou-se evidenciar esta incapacidade do antitruste em acompanhar a velocidade de mercados cada vez mais dinâmicos, bem como alcançar todos os problemas concorrenciais, especialmente, aqueles ocasionados por meios não-convencionais, isto é, por mecanismos de diferenciação de produtos, por práticas apoiadas em facilitações institucionais, subsídios estatais, obtenção de vantagens por influência no processo legislativo e, entre outros, por meio de decisões administrativas e/ou regulatórias. A competition advocacy (promoção da concorrência) foi apresentada como uma das respostas possíveis do direito para mitigar o risco de que a excessiva concentração do poder econômico acabe gerando o bloqueio de canais democráticos, a captura das instituições políticas por grupos dominantes e, ainda que reflexamente, o aumento da desigualdade. Considerando que a competition advocacy parte de uma ideia residual ou de exclusão em relação à função preventiva e à repressiva, a pesquisa identificou quais seriam os assuntos adequados para uma abordagem sistêmica e, principalmente, útil da promoção da concorrência, tendo em vista, especialmente, o tratamento ainda difuso do tema por parte da doutrina. Em conclusão, buscou-se definir, com maior precisão, o conteúdo jurídico da promoção da concorrência e foram apresentadas propostas para aperfeiçoamento do instituto no Brasil, de modo a contribuir para o desenvolvimento econômico-social e para o fortalecimento das instituições democráticas.

Palavras-chave: Promoção da concorrência, competition advocacy, advocacia da concorrência, antitruste e defesa da concorrência. 


\begin{abstract}
SILVA, Pedro Aurélio de Queiroz Pereira da. Competition and development: a Competition Advocacy in Brazil and its contribution to the strengthening of democratic institutions. 2017. 326 f. Dissertação (Mestrado) - Faculdade de Direito de Ribeirão Preto, Universidade de São Paulo, Ribeirão Preto, 2017.

This work intended to evaluate whether competition law, as built in the present, has proved to be sufficient to reach the competitive phenomenon in an effective way and, therefore, if it achieves its mission, that is, to contribute to the development and democracy. It also aimed to demonstrate that competition law's conventional tools (enforcement mechanisms) would be unable to cope with the growing concentration of markets and the elimination or even reduction of competitive distortions indirectly caused by the State itself. It has been shown that these problems are impacting on a democracy ideal and jeopardizing economic and social development. From the theoretical framework used, this antitrust inability was observed, to monitor the speed of increasingly dynamic markets, as well as to reach all competitive problems, especially those caused by non-conventional means, that is, by mechanisms of differentiation of products, malpractices supported by institutions, state subsidies, obtaining advantages by influence in the legislative process and, among others, through administrative and/ or regulatory decisions. Competition advocacy was presented as one of the possible answers to diminish the risk that the excessive concentration of economic power would end up blocking democratic channels, resulting on the capture of political institutions by dominant groups, and even if at an indirect way, increasing inequality. Considering that competition advocacy is based on a residual idea of the preventive and repressive functions, the dissertation identified what would be the appropriate subjects for systemic and useful approach to promoting competition, specially, due to the still diffuse treatment of the subject by the doctrine. In conclusion, we tried to define the legal content of the competition advocacy. We made also proposals for the improvement of the subject in brazil in order to contribute to economic and social development as well as to the strengthening of democratic institutions.
\end{abstract}

key-words: competition advocacy, competition law, antitrust and enforcement mechanisms. 
SIGLAS E ABREVIATURAS

AC - Ato de Concentração

AED - Análise Econômica do Direito

AIR - Análise de impacto regulatório

ANA - Agência Nacional de Águas

ANAC - Agência Nacional de Aviação Civil

ANATEL - Agência Nacional de Telecomunicações

ANCINE - Agência Nacional do Cinema

ANEEL - Agência Nacional de Energia Elétrica

ANP - Agência Nacional do Petróleo, Gás Natural e Biocombustíveis

ANTAQ - Agência Nacional de Transportes Aquaviários

ANTT - Agência Nacional de Transportes Terrestres

ANVISA - Agência Nacional de Vigilância Sanitária

BNDES - Banco Nacional de Desenvolvimento Econômico e Social

BRE - Better Regulation Executive, Reino Unido

CADE - Conselho Administrativo de Defesa Econômica

CAMEX - Câmara de Comércio Exterior

CB - Competition Bureau, Canadá

CC - Competition Commission, Reino Unido

CE - Comissão Europeia

CEE - Comunidade Econômica Européia

CFC - Centro de Formação de Condutores

CMA - Competition \& Markets Authority, Reino Unido

COGAP - Coordenação-Geral de Análise de Promoções Comerciais e Regulação de Loterias, SUDEP, SEAE

COGCI - Coordenação-Geral de Comércio Internacional, SUDEP, SEAE

COGCR - Coordenação-Geral de Advocacia da Concorrência em Setores Regulados, SUCON, SEAE

COGEN - Coordenação-Geral de Energia, SUINFRA, SEAE

COGPC - Coordenação-Geral de Promoção da Concorrência, SUCON, SEAE

COGTL - Coordenação-Geral de Transporte e Logística, SUINFRA, SEAE 
COGUN - Coordenação-Geral de Infraestrutura Urbana e Recursos Naturais, SUINFRA, SEAE

CPB - Competition Promotion Branch

DEE - Departamento de Estudos Econômicos do CADE

Denatran - Departamento Nacional de Trânsito

Detran - Departamento Estadual de Trânsito

DOJ - Department of Justice, Estados Unidos

DOT - U.S. Department of Transportation

DOU - Diário Oficial da União

ESAF - Escola de Administração Fazendária, Ministério da Fazenda

FCC - Federal Communications Commission

FERC - Federal Energy Regulatory Commission

FTC - Federal Trade Commission, Estados Unidos

ICN - International Competition Network

LDC - Lei de Defesa da Concorrência - Lei 12.529/11

MDIC - Ministério do Desenvolvimento, Indústria e Comércio Exterior

MF - Ministério da Fazenda

MPF - Ministério Público Federal

NCRA - National Cooperative Research Act of 1984 (EUA)

NCRPA - National Cooperative Research and Production Act of 1993 (EUA)

NEI - Nova Economia Institucional

OCDE - Organização para a Cooperação e Desenvolvimento Econômico

OFT - Office of Fair Trading, Reino Unido

OIRA - Office of Information and Regulatory Affairs, OMB, Estados Unidos

OMB - Office of Management and Budget, Estados Unidos

P\&D - Pesquisa e Desenvolvimento

PA - Processo Administrativo

PL - Projeto de lei

PROCADE - Procuradoria Geral do CADE

PROCON - Órgão Público de Proteção e Defesa do Consumidor

SBDC - Sistema Brasileiro de Defesa da Concorrência 
SDE - Secretaria de Direito Econômico

SEAE - Secretaria de Acompanhamento Econômico, Ministério da Fazenda

STF - Supremo Tribunal Federal

STJ - Superior Tribunal de Justiça

SUCON - Subsecretaria de Análise Econômica e Advocacia da Concorrência, SEAE

SUDEP - Subsecretaria de Concorrência Internacional e Defesa da Economia Popular, SEAE

SUINFRA - Subsecretaria de Regulação e Infraestrutura, SEAE

TCU - Tribunal de Contas da União

UE - União Européia

UNCTAD - United Nations Conference on Trade and Development 


\section{SUMÁRIO}

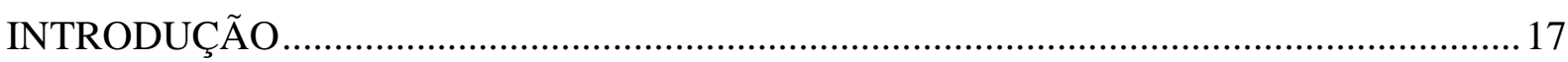

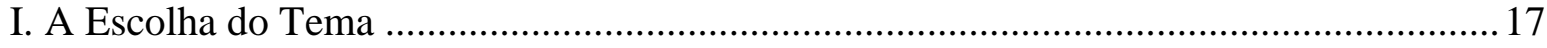

II. O Ponto de Partida da Pesquisa e a Relevância do Tema .............................................. 18

1. MÉTODO E PROCESSO INVESTIGATIVO ..................... Erro! Indicador não definido.

1.1 Em Busca de Novos Paradigmas Científicos ................... Erro! Indicador não definido.

1.2 O Referencial Teórico da Pesquisa .................................. Erro! Indicador não definido.

1.3 O Problema e a Hipótese da Pesquisa ............................. Erro! Indicador não definido.

1.4 O Que Propomos.......................................................... Erro! Indicador não definido.

1.5 Desenho Metodológico da Pesquisa .............................. Erro! Indicador não definido.

2. A PESQUISA EM DIREITO ECONÔMICO E OS FINS DO ANTITRUSTE: A NECESSÁRIA CORREÇÃO DE ROTA DA TUTELA CONCORRENCIAL ................. Erro! Indicador não definido.

2.1 O Desafio Proposto Erro! Indicador não definido.

2.2 O Direito e a Pesquisa em Direito Econômico Erro! Indicador não definido.

2.3 Os Fins do Antitruste: por que o Direito da Concorrência deveria revisitar seus pressupostos e o papel da advocacy na correção de rota da tutela concorrencial........... Erro! Indicador não definido.

2.3.1 Entre Liberdade e Equidade: os Pressupostos das Teorias Econômicas que Fundamentam o Antitruste; Erro! Indicador não definido.

2.3.2 O Difícil Equilíbrio entre Eficiência, Igualdade e Liberdade: o Papel da Tutela Concorrencial Erro! Indicador não definido. 2.3.3 Os Pressupostos Decisórios do Antitruste: o Princípio da Incerteza, a Causalidade e o Paradoxo de Schrödinger Erro! Indicador não definido.

2.3.4 Fechamento do Capítulo: A Necessária Correção de Rota do Antitruste Erro! Indicador não definido.

3. OS PRESSUPOSTOS DA COMPETITION ADVOCACY: A DIMENSÃO TRANSVERSAL DO DIREITO DA CONCORRÊNCIA ....... Erro! Indicador não definido.

3.1 Movimento Antitruste e Promoção da Concorrência....... Erro! Indicador não definido.

3.2. Concorrência, Democracia e Desenvolvimento. Erro! Indicador não definido.

3.2.1 Instituições, Custos de transação e Promoção da Concorrência Erro! Indicador não definido.

3.2.2 A Concorrência como Pressuposto Democrático e a Democracia como Pressuposto Concorrencial Erro! Indicador não definido.

3.2.3 Concorrência e Políticas de Desenvolvimento: o Difícil Equilíbrio entre Eficiência Estática e Dinâmica. Erro! Indicador não definido. 
3.2.4 Superando o Trade-off entre Eficiência Estática e Dinâmica por meio da Promoção da Concorrência. Erro! Indicador não definido.

3.2.5 Política Industrial e Disfuncionalidade Concorrencial Erro! Indicador não definido.

3.2.6 Os Fins da Política Industrial e a Promoção Concorrência....... Erro! Indicador não definido.

3.2.7 Corrupção e Promoção da Concorrência

Erro! Indicador não definido.

3.3 O Mito da Concorrência Via Preços e os Riscos da Análise com Foco em Eficiência Estática.

Erro! Indicador não definido.

3.4 A Definição de Mercado Relevante e a Competition Advocacy ...... Erro! Indicador não definido.

3.4.1 A Análise de Mercado por meio da Competition Advocacy - A Incorporação do Critério Dinâmico; Erro! Indicador não definido.

3.5. As ideias de Workable Competition e Second Best Theory: as Fronteiras entre Regulação e Promoção da Concorrência Erro! Indicador não definido.

3.6 Assimetria Informacional e Advocacy Erro! Indicador não definido.

3.6.1 Diferenciação Competitiva: como a Advocacy pode Contribuir para Mitigar

Desníveis Informacionais Erro! Indicador não definido.

3.7 A Problemática Análise de Preços no Antitruste e a Abordagem Alternativa por meio da Competitiion Advocacy Erro! Indicador não definido.

3.7.1. Promoção da Concorrência e Preços Predatórios;.... Erro! Indicador não definido. 3.7.2 Promoção da Concorrência e Preços Excessivos ...... Erro! Indicador não definido. 3.9. Promoção da Concorrência e Macroeconomia .... Erro! Indicador não definido. 3.10 Promoção da Concorrência e Mercados Dinâmicos ...... Erro! Indicador não definido. 3.10.1 A Internet das Coisas e a Tendência ao Custo Marginal Zero Erro! Indicador não definido.

3.10.2 O Tempo do Direito e o Tempo Econômico Erro! Indicador não definido.

3.11 Advocacy e Concorrência Bancária Erro! Indicador não definido.

3.12 Fechamento do Capítulo: a Transversalização da Tutela Antitruste proporcionada pela Promoção da Concorrência. Erro! Indicador não definido.

4. O CONTEÚDO JURÍDICO DA COMPETITION ADVOCACY........ Erro! Indicador não definido.

4.1 Introdução Erro! Indicador não definido.

4.2 A Inserção Legal da Competition Advocacy no Direito Positivo .... Erro! Indicador não definido.

4.3 O Princípio da Livre Concorrência como Pressuposto Legitimador da Advocacy... Erro! Indicador não definido. 
4.4 O Princípio da Livre Concorrência não se resume ao SBDC Erro! Indicador não definido.

4.6 O Conceito Jurídico de Competition Advocacy Erro! Indicador não definido.

4.6.1 A Evolução do Conceito Erro! Indicador não definido.

4.6.2 Competition Advocacy: em Busca de um Conceito Mais Atual...... Erro! Indicador não definido.

4.6.3 Caráter Distintivo da Promoção da Concorrência..... Erro! Indicador não definido. 4.7 A Promoção da Concorrência pela SEAE no contexto da Lei 8.884/94 Erro! Indicador não definido.

4.8 A Sistematização da Função de Promoção da Concorrência (Competition Advocacy) a partir da Atual LDC Erro! Indicador não definido.

4.9 O exercício da Promoção da Concorrência por Meio das funções de Enforcement. Erro! Indicador não definido.

4.10 O Compliance Premiado como Técnica de Promoção da Concorrência Erro! Indicador não definido.

4.11 A Atuação Consultiva em Matéria de Advocacy pelos Órgãos do SBDC. Erro! Indicador não definido.

4.12 A Atuação como Amicus Curiae pelos órgãos do SBDC Erro! Indicador não definido.

4.13 Consultas ao CADE Erro! Indicador não definido.

4.14 O Mecanismo de Revisão de Atos de Concentração e a Promoção da Concorrência Erro! Indicador não definido.

4.15 Intervenções Estruturais por meio da Promoção da Concorrência Erro! Indicador não definido.

4.16 A Regulação Concorrencial e A Avaliação de Impacto Regulatório ... Erro! Indicador não definido.

4.17 Revisão de Atos Regulamentares e Administrativos Contrários à Concorrência... Erro! Indicador não definido.

4.19 A Experiência Internacional em matéria de Competition Advocacy .... Erro! Indicador não definido.

4.19.1 A Competition Advocacy nos EUA Erro! Indicador não definido.

4.19.2 A Competition Advocacy no Reino Unido Erro! Indicador não definido.

4.19.3 A Competition Advocacy no México Erro! Indicador não definido.

4.19.4 A Competition Advocacy no Canadá. Erro! Indicador não definido.

5. A CULTURA DA CONCORRÊNCIA NO BRASIL Erro! Indicador não definido.

5.2 A Difusão Cultural da Concorrência Erro! Indicador não definido.

5.2 A Reforma de Padrões Educacionais Erro! Indicador não definido. 
5.4 As Políticas de Reinversão Erro! Indicador não definido.

5.5 A Reforma Institucional Erro! Indicador não definido.

5.5 Democratização do Acesso à Cultura e o Papel da Concorrência ... Erro! Indicador não definido.

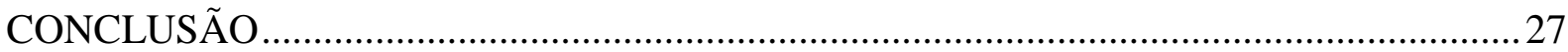

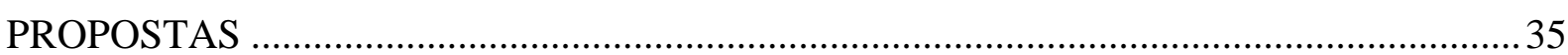

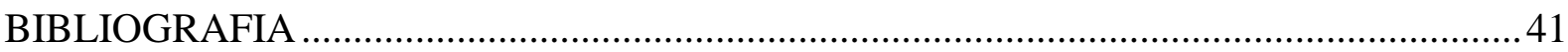




\section{INTRODUÇÃO}

\section{A Escolha do Tema}

É praticamente impossível falar da escolha do tema dessa pesquisa sem falar da trajetória que me conduziu até ele.

Muitos temas de pesquisa podem ser escolhidos a partir de uma decisão, essencialmente, racional ou de uma escolha a partir de sugestões de terceiros: orientadores ou estudiosos da matéria. A escolha da promoção da concorrência ${ }^{2}$ como tema de pesquisa, entretanto, decorre muito mais de um sentir do que de um pensar. Decorre muito mais de um contexto político e sociológico do que, propriamente, de um interesse pessoal ou apenas acadêmico. Explico.

Há muito se fala em "advocacia da concorrência". ${ }^{3}$ Esta é a expressão, comumente, utilizada pelos profissionais e estudiosos do tema na seara antitruste para designar algo próximo à promoção da concorrência e que decorre de uma tradução, no mínimo, duvidosa da expressão competition advocacy, ${ }^{4}$ muito utilizada mundo afora. Uma primeira advertência deve ser feita, em especial, para aqueles que não estão acostumados com as particularidades e expressões próprias do universo antitruste. "Advocacia da concorrência" nada tem a ver com "profissão de advogado da concorrência" ou algo que o valha. Infelizmente, a expressão já naturalizada entre os profissionais do antitruste no Brasil, além de passar uma ideia equivocada sobre seu verdadeiro sentido, talvez reduza a importância do tema. A pergunta que, certamente, vem à mente de uma pessoa do direito não acostumada com a expressão é por que um pesquisador escolheria como tema de mestrado "advocacia da concorrência”? Qual a relevância deste tema,

\footnotetext{
${ }^{2}$ Para um entendimento bastante inicial do tema, a promoção da concorrência está relacionada a atividades do Estado que objetivam combater a concentração econômica por meio de intervenções preventivas, indutoras, corretivas e educativas que não se enquadram, exatamente, nos dois controles "tradicionais" do antitruste, quais sejam, o controle repressivo de condutas contrárias à Lei de Defesa da Concorrência e o controle prévio de atos de concentração dos agentes econômicos (fusões, aquisições, acordos etc). A promoção da concorrência objetiva, entre outros, prevenir desníveis concorrenciais provocados, direta ou indiretamente, por atos do próprio Estado ou de entidades privadas com poder de influenciar a concorrência, bem como difundir a cultura da concorrência como um meio de, na via educativa, promover a internalização de condutas prócompetitivas, socialmente, benéficas.

${ }^{3}$ Como veremos, este é um termo utilizado no Brasil desde a década de 90 no contexto de liberalização econômica e introdução da concorrência, tendo sido, por vezes, referido no contexto de desestatizações e abertura de mercados.

${ }^{4}$ Como esclareceremos posteriormente.
} 
seu impacto social, sua contribuição para a democracia e para o desenvolvimento? Tentarei responder a estas perguntas por meio deste esforço investigativo. Mas além das respostas a estas indagações, por honestidade intelectual, apresento a ideia que concebo de ciência $^{5}$ e o conceito de direito $^{6}$ do qual parto. Nesse particular, tentarei demonstrar porque a pesquisa em direito econômico (especialmente, no antitruste) contém particularidades e porque estas particularidades influenciam não apenas o método, mas a própria noção que se tem do direito e como a concepção de ciência poderia contribuir para repensar o direito econômico e concorrencial.

\section{O Ponto de Partida da Pesquisa e a Relevância do Tema}

Apenas para contextualizar de modo bastante introdutório o tema no arcabouço legal do ordenamento brasileiro, é importante lembrar que o Sistema Brasileiro de Defesa da Concorrência está centrado, essencialmente, em ações de enforcement consubstanciadas em duas funções, legalmente, bem definidas: o controle de atos de concentração (função preventiva) e a repressão de condutas anticompetitivas (função repressiva), prevendo, residualmente, uma terceira função: a promoção ou advocacia da concorrência (competition advocacy). Parte desta função (de advocacy) é desempenhada pela Secretaria de Acompanhamento Econômico do Ministério da Fazenda nos termos do artigo 19 da Lei 12.529/2011. ${ }^{7}$ O Tribunal Administrativo de Defesa Econômica (TADE), órgão judicante que

\footnotetext{
${ }^{5}$ Tema discutido no primeiro capítulo como pressuposto de enfrentamento das demais questões deste trabalho.

${ }^{6} \mathrm{O}$ conceito de direito é abordado no capítulo seguinte quando tratamos da pesquisa em direito econômico.

${ }^{7}$ Nos termos do art. 19 da Lei 12.529/2011 que será, posteriormente, estudado, compete a SEAE: i. opinar, nos aspectos referentes à promoção da concorrência, sobre propostas de alterações de atos normativos de interesse geral dos agentes econômicos, de consumidores ou usuários dos serviços prestados submetidos a consulta pública pelas agências reguladoras e, quando entender pertinente, sobre os pedidos de revisão de tarifas e as minutas; ii. opinar, quando considerar pertinente, sobre minutas de atos normativos elaborados por qualquer entidade pública ou privada submetidos à consulta pública, nos aspectos referentes à promoção da concorrência; iii. opinar, quando considerar pertinente, sobre proposições legislativas em tramitação no Congresso Nacional, nos aspectos referentes à promoção da concorrência; iv. elaborar estudos avaliando a situação concorrencial de setores específicos da atividade econômica nacional, de ofício ou quando solicitada pelo Cade, pela Câmara de Comércio Exterior ou pelo Departamento de Proteção e Defesa do Consumidor do Ministério da Justiça ou órgão que vier a sucedê-lo; v. elaborar estudos setoriais que sirvam de insumo para a participação do Ministério da Fazenda na formulação de políticas públicas setoriais nos fóruns em que este Ministério tem assento; vi propor a revisão de leis, regulamentos e outros atos normativos da administração pública federal, estadual, municipal e do Distrito Federal que afetem ou possam afetar a concorrência nos diversos setores econômicos do País; vii. manifestar-se, de ofício ou quando solicitada, a respeito do impacto concorrencial de medidas em discussão no âmbito de fóruns negociadores relativos às atividades de alteração tarifária, ao acesso a mercados e à defesa comercial, ressalvadas as competências dos órgãos envolvidos; viii.
} 
compõe o CADE (Conselho Administrativo de Defesa Econômica), por sua vez, também possui papel relevante na promoção da concorrência conforme artigo $9^{\circ}$, inciso XIV, da Nova Lei de Defesa da Concorrência, devendo instruir o público sobre as formas de infração da ordem econômica. É, justamente, sobre esta terceira função (de promoção da concorrência) que nos debruçamos neste trabalho. Tomamos a liberdade de, por ora, tratar "promoção da concorrência", "competition advocacy" e "advocacia da concorrência" como sinônimos para, posteriormente, analisarmos, criticamente, qual destas denominações seria a mais adequada sob nossa ótica.

No início desta introdução, afirmo que o termo "advocacia da concorrência" tem sido utilizado para nominar "algo próximo" à promoção da concorrência e o faço, justamente, porque a "advocacia da concorrência" sempre foi tema pouco estudado e pouco compreendido até mesmo dentro do universo antitruste. A pesquisa tem como um de seus objetivos, justamente, tentar compreender o porquê desta dificuldade conceitual quanto a um instituto que, ao contrário do que possa parecer, não é novo no antitruste. ${ }^{8}$

De certa forma, porém, a novidade está na sua crescente importância e nas abordagens mais recentes que, de certa forma, ampliaram o espectro conceitual da competition advocacy no Brasil e no mundo. Por trás deste fato, certamente, há razões de ordem sócio-jurídica e razões relacionadas ao reposicionamento das teorias econômicas até então dominantes. Não por acaso muitos economistas que se contrapõem aos excessos das teorias econômicas dominantes têm sido agraciados com o prêmio Nobel ${ }^{9}$ de economia pela Academia Real de Ciências da Suécia. Podem ser citados, entre os mais conhecidos, Ronald Coase (1991), Douglass North (1993) Amartya Sen (1998), Joseph Stiglitz (2001), Oliver Williamson (2009), Elinor Ostrom (2009), Jean Tirole (2014) e, entre outros, Angus Deaton (2015). ${ }^{10}$ O prêmio de 2017 foi, justamente, para o economista Richard Thaler que, pioneiro na aplicação da teoria comportamental no

encaminhar ao órgão competente representação para que este, a seu critério, adote as medidas legais cabíveis, sempre que for identificado ato normativo que tenha caráter anticompetitivo.

${ }^{8}$ Como demonstraremos no curso deste trabalho.

9 Tecnicamente, denominado Prémio do Banco da Suécia para as Ciências Económicas em Memória de Alfred Nobel (Sveriges riksbanks pris i ekonomisk vetenskap till Alfred Nobels minne).

${ }^{10}$ Vale transcrever parte da nota da Real Academia Sueca de Ciências por ocasião da outorga do Prémio de Ciências Económicas para os economistas norte-americanos Leonid Hurwicz, Eric Maskin e Roger Myerson: "A clássica metáfora de Adam Smith sobre a 'mão invisível' refere-se a como o mercado, sob condições ideais, garante uma alocação eficiente de recursos escassos. Mas, na prática, as condições normalmente não são ideais. Por exemplo, a competição não é completamente livre, os consumidores não são perfeitamente informados e a produção e o consumo desejáveis privadamente podem gerar custos e benefícios sociais" (REUTERS: 2007).

COX, Adam. Trio norte-americano ganha Nobel de Economia 2007. Reuters Brasil, 15 de Outubro, 2007 10:38 GMT. 
campo econômico, rejeitou a racionalidade como premissa das teorias tradicionais (THE ECONOMIST: 2017b).

Com efeito, a "advocacia da concorrência" tal como, comumente, compreendida está longe de alcançar todas as intervenções possíveis em termos de promoção da concorrência. Daí porque a proposta da pesquisa se traduz em um desafio de construção conceitual da promoção da concorrência que vá além do que os estudiosos e profissionais, no geral, entendem como a conhecida (e, a um só tempo, desconhecida) advocacia da concorrência.

Embora crescente a percepção quanto à relevância do tema no Brasil e no mundo, arriscaria dizer que ainda há uma certa dificuldade conceitual quanto à delimitação do instituto. Este vazio conceitual não decorre, porém, da ausência de estudiosos de qualidade no antitruste. Muito pelo contrário. O direito concorrencial brasileiro é repleto de notáveis. A verdade é que, muito provavelmente, o contexto sócio-político funcionou como um eclipse à evolução da competition advocacy (promoção da concorrência) no Brasil. Como demonstrado no decorrer do trabalho, este bloqueio à evolução da promoção da concorrência nada mais é, na prática, que o próprio bloqueio à efetivação mais ampla do princípio da livre concorrência. Ademais disso, este "bloqueio" não parece tampouco decorrer de eventual "hipótese alternativa" de política pública consubstanciada em uma exceção legítima ao princípio da livre concorrência como instrumento de desenvolvimento social e econômico. Trata-se, deveras, de uma restrição construída no tempo sem qualquer justificativa ou embasamento de índole constitucional e, muito menos, econômico que, entretanto, criou raízes culturais.

Curiosamente, uma das características mais conhecidas do instituto da competition advocacy é, justamente, a difusão da cultura concorrencial. Mas como poderia a promoção da concorrência evoluir sem que exista no Brasil seu pressuposto, vale dizer, a própria cultura concorrencial? Daí a dificuldade e uma certa impotência da doutrina e dos órgãos de defesa da concorrência em definir de modo indutivo o que deveria passar por um processo de construção dedutiva, isto é, a partir de uma realidade concorrencial pré-existente tal como ocorreu nos EUA, país considerado precursor no antitruste. ${ }^{11}$ Doutrina antitruste (aqui incluído o trabalho

\footnotetext{
${ }^{11}$ Nas palavras de Rodas: "Embora credite-se ao Canadá o pioneirismo no estabelecimento de legislação concorrencial, graças ao Act for the Prevention and Suppression of Combinations Formed in Restraint of Trade, de 1889, coube aos Estados Unidos da América, com seu Sherman Act, de 1890, tornar ilegais todo contrato, combinações na forma de truste ou similar, ou conspiração, para restrição de comércio e monopolização. Esse mesmo país delinearia o direito antitruste e influenciaria não somente a Europa, quanto todo o mundo, a ponto de hoje, quase 100 países, possuírem seu próprio direito interno concorrencial, com inspiração maior ou menor do antitruste norte-americano. " (2015b).
} 
realizado não apenas por profissionais do direito, mas também por economistas) e órgãos que compõem o Sistema Brasileiro de Defesa da Concorrência (SBDC) são apenas uma "camada" da realidade concorrencial (ou da cultura concorrencial). Portanto, integram esta realidade e são condicionados por ela. Dito de outro modo, padrões estruturais e culturais de concorrência preexistem a "agentes" e a órgãos da concorrência, não obstante suas importantes atuações para estabelecer uma certa cultura concorrencial, para corrigir e induzir comportamentos dos agentes de acordo com o vetor concorrencial.

A escolha do tema decorre da percepção de que o direito da concorrência, tal como edificado até então, talvez esteja sendo insuficiente para fazer frente à crescente concentração de mercado nas mãos de poucos grupos econômicos, ou até mesmo incapaz de eliminar ou mesmo reduzir distorções competitivas ocasionadas muitas vezes pelo próprio Estado que, não raro, atua como um "representante" destes mesmos grupos econômicos, reforçando privilégios e poder de mercado nos mais variados segmentos. Como demonstraremos, inúmeros trabalhos recentes dão "pistas" desta incapacidade do antitruste em alcançar todos os problemas concorrenciais, especialmente, aqueles ocasionados por meios nada convencionais.

Calixto Salomão Filho, em obra seminal, fala na "paralisia do antitruste", justamente, para descrever esta incapacidade operacional do sistema e da teoria microeconômica que ampara este campo do direito em alcançarem esta realidade (2015). Obras recentes mundo afora têm demonstrado a pouca efetividade dos instrumentos concorrenciais atualmente disponíveis. ${ }^{12}$ Nesse sentido, o economista norte-americano John Kwoka, por meio de inédita investigação empírica, evidenciou a inaptidão do antitruste em produzir eficiências nas operações e mercados analisados nos últimos anos (2015). A obra de Kwoka tem provocado tamanha repercussão no âmbito acadêmico americano a ponto de Professores da Universidade de Chicago, uma escola marcadamente liberal, ${ }^{13}$ reunirem-se, recentemente, para questionar se a excessiva concentração dos mercados não estaria comprometendo a própria eficiência dos mercados. O que poucos entenderiam é como poderia haver uma aparente mudança de posição em uma escola considerada, tradicionalmente, liberal. É preciso ter em mente, entretanto, que não se trata de uma questão, puramente, ideológica, mas sim da alteração de pressupostos fáticos a partir dos quais a teoria foi produzida. Sob um prisma dinâmico, a teoria de décadas

\footnotetext{
12 Aqui incluídos os próprios conceitos microeconômicos.

${ }^{13}$ Como demonstraremos, uma escola eficientista não é, necessariamente, liberal, mas pode ter sido, oportunisticamente, liberal. Daí que o pêndulo irá se ajustar para que aqueles fins antes preconizados (pautados no apotegma eficientista) possam, novamente, ser alcançados.
} 
atrás poderia até sugerir que seria mais eficiente uma abordagem que incentivasse ganhos produtivos e alocativos advindos das concentrações para aquele momento e lugar. Como explica Zingales, Professor de Chicago, "talvez o pêndulo tenha mudado para a outra direção. Isto não significa que o ponto de vista tenha mudado em direção oposta, e sim que os fatos são, notoriamente, diferentes" (THE CHICAGO MAROON, 2017).

Posner, por sua vez, em artigo publicado em 2000, já antevia as substanciais dificuldades do antitruste em acompanhar os problemas da realidade (POSNER, 2000). Para o criador da "Law and Economics", existiriam inúmeras outras intervenções, igualmente, relevantes e uma verdadeira crise de paradigma organizacional do sistema de defesa da concorrência, de tal forma que o antitruste não estaria adaptado a lidar com o dinamismo econômico e com a nova economia (POSNER: 2000:2).

Nos EUA, estudos recentes demonstram que sucessivas ondas de concentração de empresas fizeram com que mais de dois terços da economia norte-americana se tornassem mais concentrados desde a década de 90 (THE ECONOMIST, 2017a). Jan De Loecker e Jan Eeckhout evidenciam a brutal elevação das margens de lucros das empresas norte-americanas nas últimas décadas: de 18\% em 1980 para 67\% em 2014 (2017: 9).

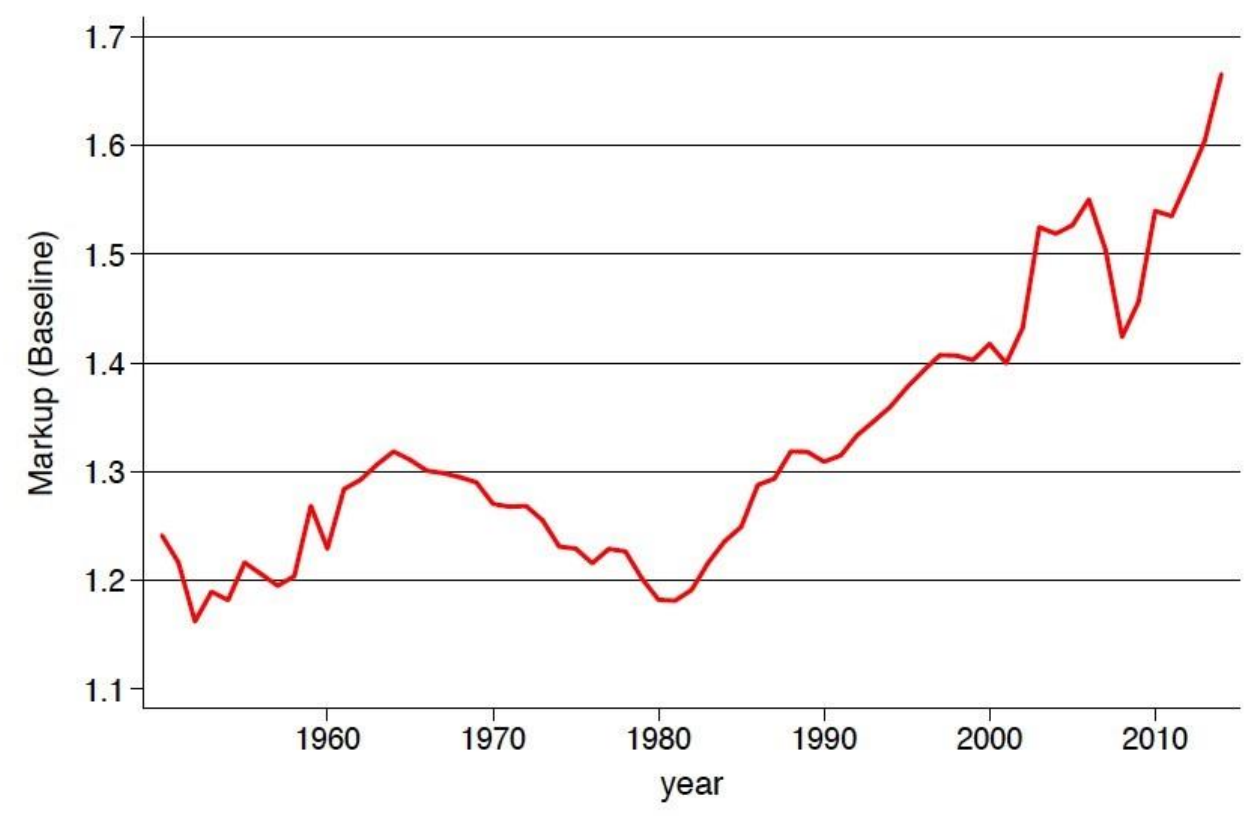

Fonte: Jan De Loecker e Jan Eeckhout (2017:09) 
Germán Gutierrez e Thomas Philippon, por sua vez, demonstram o baixo índice de investimentos privados desde 2000 a despeito de níveis recordes de lucratividade das empresas norte-americanas (2017). Um dos fatores apontados pelos autores para tal cenário é, justamente, a significativa redução do nível de competição nos mais variados setores da economia (GUTIERREZ; PHILIPPON, 2017: 66-67). Coincidentemente, indústrias como a farmacêutica, de telecomunicações e de aviação civil estariam praticando preços $50 \%$ maiores do que em outros países com retornos crescentes sobre o capital (THE ECONOMIST, 2017a). Muitos outros estudos atestam a expressiva redução dos níveis de competição e dinamismo em diversos segmentos, bem como o aumento significativo da lucratividade e da concentração econômica (DECKER ET AL., 2014 e 2015; GRULLON ET AL.2017; DOTTLING ET. AL., 2017).

Outro ponto que merece ser realçado é o de que empresas americanas gastam mais de US\$ 3 bilhões por ano com lobby (THE ECONOMIST, 2017a), o que tem elevado o risco de captura de órgãos reguladores, das autoridades concorrenciais e de influência no processo legislativo para obtenção de medidas que possam, ainda que indiretamente, limitar a concorrência. As dificuldades à efetivação da tutela antitruste vão, portanto, muito além de questões econômicas, alcançando questões de índole institucional e política.

A preocupação com a excessiva concentração nos EUA, que estaria limitando novos investimentos e inovações, fez com que até mesmo o então Presidente Barack Obama editasse uma "Executive Order", especialmente, com o intuito de promover a concorrência no país (WHITE HOUSE, 2016).

No Brasil, os graves problemas relacionados à corrupção têm colocado o sistema de defesa da concorrência no centro das atenções. Inúmeros casos envolvendo práticas de corrupção $^{14}$, não raro, estão associados a ilícitos concorrenciais (como nos cartéis em licitação) e grandes grupos econômicos investigados também pretendem, por óbvio, fazer valer seus interesses em aquisições, lobby e pressões de todo gênero. Nesse sentido, os referenciais teóricos utilizados na pesquisa ${ }^{15}$ demonstram a estreita relação de interdependência entre concorrência, desenvolvimento e democracia. Por fim, a crescente desigualdade constatada nos últimos tempos, como demonstra Piketty (2014), guardaria estreita relação com este crescente e alarmante processo de concentração econômica.

\footnotetext{
${ }^{14}$ Entre eles, as conhecidas operações Lava Jato e Zelotes deflagradas pela Polícia Federal brasileira.

${ }^{15}$ Detalhados a seguir.
} 
Como demonstraremos, Reino Unido, EUA, Canadá, México e, entre outros, Austrália vêm tentando superar esta incompletude do direito da concorrência por meio do fortalecimento, justamente, da competition advocacy (promoção da concorrência).

É preocupante constatar que, quando da escolha do tema, não havia, no Brasil, nenhuma pesquisa no âmbito acadêmico $^{16}$ que tratasse, especificamente, sobre a promoção da concorrência. A advocacy, como será visto, é considerada hoje a pedra de toque de qualquer sistema de defesa da concorrência existente no mundo (ZOGHBI, 2009: 1). Não poderia ser um assunto relegado a segundo plano entre os estudiosos do antitruste. ${ }^{17}$ A ausência de estudos sobre o tema, entretanto, tem sido, gradativamente, suplantada com a publicação esparsa de artigos, estudos e workingpapers no Brasil e no mundo nos últimos anos.

Com efeito, em artigo publicado em 2005, destacamos a insuficiência dos mecanismos tradicionais do antitruste em mitigar riscos concorrenciais do advento de novos produtos e novas tecnologias (QUEIROZ, 2005). Até então, não havia a previsão de mecanismos de análise prévia dos impactos anticompetitivos de novas tecnologias ou novas políticas públicas com exceção das funções convencionais do antitruste (controle de atos de concentração e de condutas). Além disso, não havia talvez uma compreensão mais ampla de que questões como estas poderiam ser equacionadas por meio da competition advocacy. Os debates e reflexões do antitruste giravam em torno, essencialmente, do controle de condutas anticompetitivas e de atos de concentração, restando apenas um papel secundário e, por demais, simbólico à "advocacia da concorrência".

Demais disso, como demonstraremos, o que pode estar em risco, nesse cenário de excessiva concentração e de uma certa limitação operacional do antitruste, é a própria ideia de democracia. Nesse sentido, Pitofsky ${ }^{18}$, um dos principais teóricos do antitruste na atualidade, define com precisão este sentimento:

\footnotetext{
${ }^{16}$ Mais precisamente no âmbito da pós-graduação stricto sensu no Brasil.

17 Justiça seja feita, as publicações sobre o tema têm crescido exponencialmente, porém, apenas nos últimos anos.

${ }^{18}$ Pitofsky é Professor da Universidade de Georgetown nos EUA, tendo atuado como Comissário e Diretor do Departamento de Defesa do Consumidor da Federal Trade Commission. Ou seja, trata-se de um estudioso que acompanhou boa parte da evolução do antitruste americano, servindo ao próprio governo dos EUA.
} 
O medo que a excessiva concentração de poder econômico poderá promover pressões antidemocráticas, o desejo de reduzir a margem de poder de alguns grupos privados, a fim de aumentar a liberdade individual, e o receio de que a crescente intervenção pública poderá ser necessária se a economia passar a ser dominada por poucos podem e devem ser, possivelmente, incluídas na equação antitruste. Embora as preocupações econômicas continuem sendo fundamentais, ignorar esses fatores não-econômicos seria ignorar as bases da legislação antitruste e o consenso político a partir do qual o antitruste foi edificado. ${ }^{19}$ (1979: 1075)

A competition advocacy seria, portanto, uma das respostas possíveis do direito para mitigar o risco de que a crescente concentração do poder econômico ${ }^{20}$ acabe gerando o bloqueio de canais democráticos, a captura das instituições políticas por grupos dominantes e, ainda que reflexamente, o aumento da desigualdade.

Os capítulos estão divididos da seguinte forma. No primeiro, são tecidas considerações sobre a opção metodológica, sobre a investigação empreendida e, especialmente, sobre o conceito de ciência tomado como ponto de partida. Nesse particular, a reflexão realizada é fundamental para questionar dogmas e pressupostos que fundamentam o antitruste. No segundo, tratamos das particularidades da pesquisa em direito econômico e dos fins da tutela antitruste, objetivando, justamente, revisitar conceitos sedimentados na teoria concorrencial e, dessa forma, erigir fundamentos mais sólidos para (re)construção de uma teoria concorrencial. No terceiro, a partir do referencial teórico utilizado, das hipóteses primárias e das teorias políticas e econômicas, passa-se a contextualizar o problema e, a partir do referencial teórico e das principais teorias econômicas, a investigar essa aparente incapacidade do antitruste em alcançar, de modo mais amplo, o fenômeno concorrencial. Buscamos também demonstrar que, nos dias de hoje, a competition advocacy ocupa papel central para a concretização mais efetiva do princípio constitucional da livre concorrência, funcionando como mecanismo para mitigar

\footnotetext{
19 "The fear that excessive concentration of economic power will foster antidemocratic political pressures, the desire to reduce the range of private discretion by a few in order to enhance individual freedom, and the fear that increased governmental intrusion will become necessary if the economy is dominated by the few, can and should be feasibly incorporated into the antitrust equation. Although economic concerns would remain paramount, to ignore these non-economic factors would be to ignore the bases of antitrust legislation and the political consensus by which antitrust has been supported" (PITOFSKY, 1979: 1075). Destacamos.

${ }^{20}$ Nos EUA, país berço do antitruste, estudos recentes demonstram que sucessivas ondas de concentração de empresa fizeram com que mais de dois terços da economia norte-americana se tornassem mais concentrados desde a década de 90 (THE ECONOMIST, 2017). Coincidentemente, indústrias como a farmacêutica, de telecomunicações e de aviação civil estão praticando preços $50 \%$ maiores do que em outros países com retornos crescentes sobre o capital. Ao mesmo tempo, as empresas americanas gastam mais de US\$ 3 bilhões por ano com lobby, o que tem elevado o risco de captura de órgãos reguladores (THE ECONOMIST, 2017).
} 
privilégios econômicos, reduzir a desigualdade e para permitir o fortalecimento de práticas e instituições democráticas. No quarto capítulo, passamos a tratar da questão conceitual, propriamente dita, da "advocacia da concorrência", de modo a propor uma definição desta função, bem como para apresentar uma proposta de sistematização dos mecanismos que a integram. Nesse mesmo capítulo, trazemos a contribuição teórica sobre a competition advocacy em outras partes do mundo, organismos internacionais e órgãos de defesa da concorrência. Nesse particular, não se trata de detalhar cada um dos mecanismos, até porque renderiam, certamente, pesquisas específicas, mas de compreender sua "razão de ser", "por que" e "como" constituem manifestações da competition advocacy. Exemplos de casos concretos serão explicitados como apoio para compreensão desses mecanismos e dos limites enfrentados pelo antitruste. Vale dizer, a análise de casos não constitui objetivo central do trabalho, mas é relevante para compreensão, ainda que de modo auxiliar, do conceito proposto de competition advocacy e dos limites do antitruste no Brasil. No quinto e último capítulo, é examinada a dimensão cultural ${ }^{21}$ da competition advocacy e, com base em uma análise propositiva, são sugeridos meios para viabilização do instituto no Brasil (difusão cultural, educacional, reforma institucional etc). Por fim, são apresentadas propostas para aperfeiçoamento do instituto e uma breve conclusão.

\footnotetext{
${ }^{21}$ Incluído nesta dimensão o importante papel educativo da advocacy.
} 


\section{CONCLUSÃO}

A presente pesquisa objetivou evidenciar que o direito da concorrência, tal como edificado no presente, talvez esteja sendo insuficiente para fazer frente à crescente concentração de mercado e incapaz de eliminar ou mesmo reduzir distorções competitivas ocasionadas, ainda que indiretamente, pelo próprio Estado. Como demonstramos, inúmeros trabalhos recentes atestam esta incapacidade do antitruste em alcançar todos os problemas concorrenciais, especialmente, aqueles ocasionados por meios não-convencionais, isto é, por mecanismos de diferenciação de produtos, práticas apoiadas em facilitações institucionais, subsídios estatais, obtenção de vantagens indiretas por influência no processo legislativo e, entre outros, por decisões administrativas ou regulatórias.

Esta incapacidade operacional do antitruste tem provocado tamanha preocupação que, até mesmo, estudiosos de escolas, tradicionalmente "liberais" como da Universidade de Chicago, tem-se questionado sobre esta excessiva concentração e sobre o arrefecimento da concorrência nos mais variados segmentos (THE CHICAGO MAROON, 2017).

Demonstrou-se que o SBDC está centrado, essencialmente, em suas tradicionais funções, legalmente, bem definidas: o controle de atos de concentração (função preventiva) e a repressão de condutas anticompetitivas (função repressiva). Existiriam, entretanto, "pontos cegos" de aplicação da livre concorrência que as tradicionais funções já não conseguiriam alcançar. ${ }^{22}$ As estratégias anticompetitivas se sofisticaram e muitos desvios são, indiretamente, amparados por atuações ou omissões do próprio Estado. Mas não apenas isso. A defesa da concorrência já não estaria mais se revelando, totalmente, apta ao alcance de seu objetivo inicial, qual seja, a efetivação ampla do princípio da livre concorrência. Seus mecanismos, de caráter, essencialmente, reativo e estático, já não conseguiriam alcançar os problemas concorrenciais tal como antes se preconizava.

Buscou-se também ressaltar não apenas o papel central da concorrência para o desenvolvimento, como geralmente preconizado, mas também sua contribuição para o fortalecimento das instituições democráticas. Nesse sentido, a aptidão do antitruste em promover a democracia depende de uma abordagem que ultrapasse a mera consideração de benefícios imediatos advindos de ganhos de eficiência estática e também do modo de efetivação

\footnotetext{
${ }^{22}$ Aqui não se trata de uma crítica aos operadores do setor, mas sim ao desenho institucional, até porque, estou certo, a vontade geral dos profissionais e estudiosos do antitruste seria uma atuação muito mais ampla e fortalecida.
} 
da tutela antitruste, isto é, da suficiência de seus mecanismos para um controle mais amplo e dinâmico. A consideração de que existe (ou que pode existir) um componente democrático relevante no antitruste importa a própria mudança da concepção atual de tutela concorrencial e revela um aparente trade off entre uma concepção que privilegia crescimento puro e simples e outra que valorizaria o crescimento, social e economicamente, sustentável. Este trade off, entretanto, como asseveramos, seria apenas aparente na medida em que supostas "eficiências" no presente, que impliquem perdas democráticas, revelar-se-ão verdadeiros problemas no futuro, vale dizer, uma espécie de externalidade negativa advinda de estruturas excessivamente, concentradas que passariam a produzir mais efeitos negativos do que aqueles, inicialmente, considerados positivos. Somente uma análise evolucionária (não-estacionária) poderia dar conta deste fenômeno adequadamente.

A verdade é que a qualificação "democrática" do desenvolvimento é o que permitiria a efetiva incorporação do crescimento de forma duradoura e disseminada pela sociedade. Prevenir a excessiva concentração do poder econômico talvez não tenha sido uma das preocupações recentes dos sistemas de defesa da concorrência, o que pode ter comprometido sua função de democratização das instituições (PETERSEN, 2011: 22). Se é verdade que a concorrência, comprovadamente, contribui para o desenvolvimento econômico, é verdade também que o qualifica. Isto é, os fins do antitruste influenciam "qual" modelo de desenvolvimento deve ser perseguido pelo Estado: um modelo mais ou menos inclusivo, mais ou menos democrático. Obviamente que quando falamos de um padrão concorrencial não nos referimos, exatamente, ao específico papel do SBDC, também relevante, mas ao sistema concorrencial como um todo presente na configuração de políticas de desenvolvimento. Sendo a concorrência central ao desenvolvimento e um imperativo constitucional, a ausência de preocupação concorrencial nessas políticas seria, ultima ratio, uma escolha por um dado padrão de desenvolvimento, ainda que muitas vezes, realizada de modo implícito ou indireto.

Assim, buscamos demonstrar que a capacidade de um sistema concorrencial mitigar a excessiva concentração econômica e prevenir pressões antidemocráticas depende, essencialmente, de como este aparato é desenhado e vivenciado institucionalmente. Talvez o sistema tradicional de defesa da concorrência reproduza, justamente, um modo de operar focado em resolução de questões pontuais, atuando de forma essencialmente reativa, incapaz, portanto, de concretizar mais amplamente os fins esperados de uma tutela antitruste. Deve-se questionar, assim, qual a capacidade do sistema de defesa da concorrência atual para contribuir para o desenvolvimento e para a democracia. 
Nesse sentido, a reforma legal do SBDC pode ter representado um importante passo para aperfeiçoamento das instituições, mas talvez ainda exista um longo caminho a ser percorrido até que a concorrência se apresente, de fato, como elemento central ao desenvolvimento social e econômico do Estado Democrático. É importante lembrar, entretanto, que a reforma do sistema concorrencial que resultou na "nova" LDC se iniciou em agosto de 2000 após o aperfeiçoamento de anteprojetos que já buscavam introduzir muitas das modificações incorporadas na Lei $12.529 / 2011 .^{23}$

Vale dizer, os avanços verificados na LDC foram fruto de pleitos de longa data que, por certo, captaram apenas, parcialmente, novas demandas advindas de um contexto político e econômico que se transformou rapidamente nas últimas duas décadas. O processo de rápida integração entre a velha e nova economia por meio do advento da "internet das coisas", o surgimento de novas tecnologias e novos produtos, a rápida transformação da dinâmica de custos e do mercado de trabalho, as profundas alterações das teorias econômicas e os problemas advindos da corrupção sistêmica demandam um olhar renovado do antitruste para lidar, de modo mais amplo e dinâmico, com o fenômeno concorrencial sob pena de inefetividade no cumprimento do desiderato constitucional. A promoção da concorrência seria, justamente, a contrapartida para lidar com a questão concorrencial de modo mais amplo e efetivo.

Uma intervenção renovada em termos de promoção da concorrência pode-se traduzir em uma intervenção muito mais estratégica e efetiva do que métodos tradicionais de defesa da concorrência e de regulação setorial. Isto porque se consubstanciaria em uma atuação tempestiva, indutora de comportamentos e preventiva. Além disso, a promoção da concorrência é concretizada, por vezes, por instrumentos, em alguma medida, consensuais ${ }^{24}$ (ainda que com apoio indireto da "ameaça" dos mecanismos sancionatórios) em substituição à aplicação de multas pecuniárias $^{25}$, de modo articulado com medidas impositivas e, como já referido, pelos mais variados meios preventivos e de soft law. Um mecanismo geral de promoção da concorrência prescindiria, em muitos casos, de mecanismos de hard law, normalmente, adotados ex post ${ }^{26}$ e, não raro, inefetivos.

Além disso, uma função geral de advocacy bem estruturada exigiria menos regulação, pois o acompanhamento permanente de determinados mercados já seria uma forma de

\footnotetext{
23 Mais especificamente pelo Grupo de Trabalho Interministerial criado por decreto em 11 de agosto de 2000.

${ }^{24}$ Na prática, muitas vezes, impositivos.

25 Tanto em sentido amplo, na medida em que uma atuação preventiva evitaria ilícitos concorrenciais, como em sentido estrito, por meio da instrumentalização de acordos premiais para reduzir ou substituir punições.

${ }^{26}$ Em virtude da prevenção dos danos que já não precisariam ser controlados posteriormente.
} 
identificar e inibir estruturas ineficientes e pouco competitivas. Mas como já foi pontuado, os limites entre a intervenção regulatória e a concorrencial ainda não foram, suficientemente, estudados (COASE, 2016), o que dificultaria a avaliação da necessidade de mais ou menos regulação em muitos casos. A promoção da concorrência consubstanciar-se-ia em alternativa para que o controle da regulação ocorresse de modo contínuo por meio do acompanhamento dos mercados, de pressupostos de eficiência e de padrões de otimalidade concorrencial.

A ideia mais adequada seria identificar advocacy não apenas com difusão da cultura da concorrência e nem como "residual" às tradicionais funções de enforcement como, de resto, aqui preconizado. Da mesma forma, importa reconhecer um papel mais relevante à promoção da concorrência que não se restrinja a funções passivas e que também seja, eventualmente, instrumentalizadora de meios impositivos e coercitivos, não dissociada, portanto, das funções de enforcement.

Daí porque definimos a promoção da concorrência como a função de natureza dinâmica e intertemporal que objetiva calibrar o grau de competição e de eficiência nos mercados, bem como corrigir distorções concorrenciais em setores econômicos por meio de mecanismos que podem ou não envolver as conhecidas funções de enforcement e que, devido a sua natureza transversal, pode ser implementada por diferentes órgãos, entes da Federação e esferas de Poder, mas de acordo com suas competências originárias.

A diferença básica em relação às funções típicas do antitruste, portanto, é que não se trata de uma função com natureza, meramente, adjudicatória, isto é, que objetive resolver, pontualmente, um problema concorrencial com a aplicação de multa ou com a aprovação de uma operação com base em um referencial estático-temporal. Daí porque a competition advocacy pressupõe mais que resolução de conflitos, mas a própria realização de um controle concorrencial do mercado de forma continua e não limitado à atuação formal dos órgãos do SBDC. Não existe, portanto, uma oposição entre a tutela concorrencial tradicional e a promoção da concorrência, mas, essencialmente, uma complementaridade na medida em que a promoção é mais ampla e difusa. Além disso, a promoção da concorrência impõe uma mudança de enfoque na própria aplicação do controle tradicional na medida em que promove uma valorização do conceito de eficiência dinâmica e pressupõe, por conseguinte, um questionamento sobre a efetividade da utilização dos atuais instrumentos de intervenção ${ }^{27}$ para

\footnotetext{
${ }^{27}$ Nomeadamente, a aplicação de multa pura e simples ou a mera imposição de condições à aprovação de uma operação.
} 
satisfação do princípio constitucional da livre concorrência. Como vimos, esta nova postura importa uma releitura até mesmo dos conceitos relacionados à análise de mercado relevante e, portanto, de poder de mercado. A promoção da concorrência tenta aproximar o tempo do direito ao tempo econômico contanto que o direito sirva a soluções mais efetivas do que as atualmente disponíveis. Somente uma análise que contemple a dimensão institucional e intertemporal dos mercados permitiria ao direito, de fato, "alcançar" o fenômeno concorrencial.

Com efeito, as teorias de décadas atrás poderiam sugerir que seria mais eficiente uma abordagem que incentivasse ganhos produtivos e alocativos advindos das concentrações. Mas, sob um prisma dinâmico, que tentamos valorizar no nosso trabalho, é a excessiva concentração de mercado que pode estar comprometendo a própria eficiência econômica. Para Zingales, Professor de Chicago, "talvez o pêndulo tenha mudado para a outra direção. Isto não significa que o ponto de vista tenha mudado em direção oposta, e sim que os fatos são, notoriamente, diferentes" (THE CHICAGO MAROON, 2017). Além disso, a rápida transformação da economia com a tendência à drástica redução do custo marginal estaria a alterar todos os pressupostos de eficiência que sempre nortearam a análise antitruste como, de resto, tentamos demonstrar nesta investigação (RIFKIN, 2016).

Como se demonstrou, outro problema é o de que muitos identifiquem a aplicação do princípio da livre concorrência com ações apenas dos órgãos que compõem o SBDC (Sistema Brasileiro de Defesa da Concorrência). Seria possível, entretanto, por meio da promoção da concorrência, vislumbrar a aplicação do princípio da livre concorrência para além dos órgãos do SBDC. Isto, por uma razão muito simples, todos somos responsáveis pela observância do vetor concorrencial assim como devemos observar, diariamente, o princípio da legalidade ou da igualdade independentemente do uso da força ou do enforcement jurisdicional. Isto é, a livre concorrência não é um princípio restrito aos especialistas na matéria. Os órgãos do SBDC são órgãos oficiais destacados especialmente para reforço da livre concorrência, princípio que, por imposição constitucional, deveria, entretanto, ser por todos observado. Além disso, vale ressaltar que a livre concorrência deveria ser abordada não apenas como princípio do direito econômico e do antitruste, mas observável, com as devidas ponderações, em relação a outros princípios, em disciplinas que tratem de obrigações e contratos, tributação (v.g.: extrafiscalidade e neutralidade tributária), crimes contra a ordem econômica e, entre outros, no direito administrativo (licitações, contratos, agências reguladoras etc). 
A abordagem minimalista do antitruste, pressuposta na teoria tradicional, teve como efeito transformar, ainda que involuntariamente, a parte (microssistema) no todo (toda a realidade concorrencial), de tal sorte que a temática concorrencial acabou, de certa forma, insulada nos órgãos oficiais de controle. Por tal razão, seria necessário transversalizar a tutela antitruste, pois também transversal é o princípio da livre concorrência em sua essência. A tutela deve refletir seu desiderato e não permanecer insulada em um microssistema, infelizmente, incapaz de alcançar a realidade concorrencial. Mas a verdade é que esta mudança de enfoque pode e deve ocorrer a partir dos próprios atores formais do SBDC, de modo a que, uma vez "desinsulada", a tutela concorrencial se amplie e atinja sua finalidade interdepartamental. Sem dúvida, esta ampliação do escopo antitruste trará novos desafios e mais trabalho para advogados e economistas, mas isto não é, necessariamente, ruim, até porque o controle concorrencial irá se ampliar e trazer benefícios para toda a sociedade.

Talvez um ponto sensível à difusão da cultura concorrencial é a necessidade de valorização da dimensão educativa da função promocional. Sem a reforma de padrões educacionais e curriculares, especialmente, nas Faculdades de Direito, Administração e Economia, para que seja valorizada a temática antitruste, dificilmente, haverá terreno propício para enraizar a cultura da concorrência no Brasil. Nesse sentido, "uma vigorosa cultura competitiva é o marco característico de um bem-sucedido regime concorrencial e a competition advocacy é o pré-requisito básico para que isso aconteça” (ZOGHBI, 2009: 1). ${ }^{28}$

De mais a mais, a despeito de central ao desenvolvimento e à democracia, o antitruste não vem merecendo um tratamento à altura de seu status constitucional e econômico. Somente em 2015, o CADE arrecadou R \$ 524 milhões (CADE, 2016). O orçamento do CADE, entretanto, foi de apenas R \$ 22 milhões. Para se ter uma ideia, o orçamento da ANATEL para o mesmo ano foi de cerca de R\$ 500 milhões e da ANCINE de R\$ 56 milhões. ${ }^{29}$ Todos superiores ao CADE. Obviamente que a arrecadação do CADE nem de longe corresponde aos benefícios econômicos e sociais da sua atuação, até porque sua finalidade não seria, exatamente, arrecadatória. Por outro lado, a arrecadação em questão é apenas uma pequena amostra dos potenciais benefícios de uma atuação mais ampla em torno do princípio concorrencial.

\footnotetext{
${ }^{28}$ No original: "a healthy competition culture is the halmark of a good competition regime and competition advocacy is a basis pre-requisite for that" (ZOGHBI, 2009: 1)

${ }^{29}$ Mas o que seria mais benéfico à sociedade? Destinar recursos para mais intervenções regulatórias ou investir em promoção da concorrência? Esta é uma pergunta que, curiosamente, os próprios mecanismos de advocacy poderiam responder com a demonstração empírica do custo de intervenções supressivas da competição vis a vis seus supostos benefícios.
} 
Para se ter uma ideia do impacto direto da promoção da concorrência para os cofres públicos, como evidenciamos, somente a AGU ajuizou ações para recuperar R $\$ 11,3$ bilhões ${ }^{30}$ contra envolvidos em práticas de cartel em licitações. ${ }^{31}$ Por meio de acordos de leniência assinados pela AGU e CGU com empresas investigadas nas recentes operações da Polícia Federal, espera-se arrecadar valores ainda maiores. ${ }^{32}$ A atuação preventiva do TCU com base na livre concorrência, sem dúvida, também tem gerado expressiva economia para os cofres públicos e esta atuação pode e deve ser ampliada para os demais órgãos de controle presentes nas outras esferas federativas. De toda forma, é no mínimo, incompreensível que o SBDC detenha um orçamento que não chega nem mesmo a um décimo do que arrecada. Para incorporar funções mais amplas de promoção da concorrência, o CADE deveria ter um orçamento compatível com a relevância e alcance dessa função. ${ }^{33}$ Reconhece-se, todavia, que seria uma tarefa inglória investir em um mecanismo de difusão da concorrência se a maior parte dos incentivos institucionais, no mais das vezes, originados do próprio Poder Público, caminham, justamente, na direção oposta, isto é, são indutores de um ambiente institucional contrário à livre concorrência.

Por fim, cumpre concluir que, na realidade, o que pode estar em risco com a crescente concentração de poder econômico, redução da concorrência e crescente aumento da desigualdade nas últimas décadas ${ }^{34}$ é a própria democracia. ${ }^{35}$ A competition advocacy surgiria, portanto, como pilar de sustentação de um efetivo ambiente institucional de maior competição no Brasil, contributo para o desenvolvimento, mas também como um imperativo democrático.

\footnotetext{
${ }^{30}$ Ação de Improbidade Administrativa 5017254-05.2017.4.04.7000.

${ }^{31}$ Certamente, este valor poderia ter sido muito maior caso o órgão detivesse conhecimento e atuação frequente em ações judiciais do gênero na matéria concorrencial.

${ }^{32}$ É certo que muitas das práticas de corrupção estão associadas práticas anticompetitivas e, nem sempre, o prejuízo "imediato" alcança o prejuízo para o mercado, de tal sorte que ações judiciais são necessárias não apenas para recuperar quantias, mas para restabelecer o equilíbrio nos mercados.

${ }^{33} \mathrm{O}$ CADE arrecadou R $\$ 524$ milhões (CADE, 2016). Isto sem contar valores arrecadados em acordos de leniência assinados pela AGU e CGU em questões anticorrupção, por vezes, associadas à práticas anticompetitivas.

${ }^{34}$ A propósito, conferir Piketty (2014).

${ }^{35}$ Nesse sentido, PITOFSKY $(1979,: 1075)$ afirma: "the fear that excessive concentration of economic power will foster antidemocratic political pressures, the desire to reduce the range of private discretion by a few in order to enhance individual freedom, and the fear that increased governmental intrusion will become necessary if the economy is dominated by the few, can and should be feasibly incorporated into the antitrust equation. Although economic concerns would remain paramount, to ignore these non-economic factors would be to ignore the bases of antitrust legislation and the political consensus by which antitrust has been supported."
} 


\section{PROPOSTAS}

A ideia de apresentar propostas para a implementação mais efetiva do princípio da livre concorrência, nomeadamente, por meio de ferramentas promocionais, tem muito mais por intuito iniciar uma discussão e reflexão mais profunda sobre a necessidade de revisão do sistema de defesa da concorrência do que, propriamente, esgotar o assunto aqui tratado. "Se", "como" e "quando" estas propostas serão viabilizadas são questões que, obviamente, exorbitam os estritos objetivos desta investigação.

O primeiro ponto a ser destacado é o de que as ações promocionais em matéria concorrencial deveriam partir, com mais frequência, não apenas do SBDC, mas também de outros níveis e órgãos: Estados, Municípios, Poder Judiciário, Legislativo, Ministério Público, advocacias públicas, agências reguladoras, tribunais de contas, órgãos de controle e Universidades que, neste particular, deveriam desempenhar papel mais ativo por meio de ações educativas. Talvez um equívoco seja acreditar que a livre concorrência não teria relevância na realidade regional e local (e, nesse particular, a importância reduzida do tema nas faculdades de Direito seria também um fator a enfraquecer a difusão nessa esfera).

Na verdade, a promoção da concorrência, no âmbito regional e local, é crucial ao desenvolvimento até para permitir a democratização das instituições. Assim, por exemplo, na realidade local, a competition advocacy cumpriria papel crucial nas instituições responsáveis por processos licitatórios ou, até mesmo, no caráter educativo de estimulo à concorrência, empreendedorismo e inovação (caraterísticas essenciais ao desenvolvimento) ou mesmo para combater desvios anticoncorrenciais em leis e regulações que favoreçam monopólios nos mais variados setores (construção civil, planos de saúde, mercado funerário, centros de formação de condutores etc).

A propósito da descentralização da tutela concorrencial, Bork já em 1978 criticava o fato de, nos EUA, os órgãos de defesa da concorrência serem localizados "apenas" nas maiores cidades e que isso implicava um distanciamento da tutela antitruste em relação às demais localidades (BORK, 1993: 406). Esta não é uma dificuldade apenas brasileira, portanto. Porém, a representatividade antitruste no Brasil é, excessivamente, minimalista e este fato, certamente, tem muito a ver com a já citada falta de consciência em relação ao papel central da concorrência para o desenvolvimento e para fortalecimento das instituições democráticas. Talvez isso possa ser atribuído também a um certo receio de que a cultura da concorrência possa gerar pressões 
nos campos políticos e econômicos ou até mesmo porque estas estruturas estejam já de tal forma acomodadas que mudar um habitus estabelecido e arraigado se revelaria uma tarefa, demasiadamente, difícil (BOURDIEU, 2008). Entretanto, há soluções alternativas como compartilhamento de estruturas com outros órgãos. A AGU, a Receita Federal e a Polícia Federal estão localizadas na maior parte dos grandes centros. Custaria muito pouco à União manter microestruturas dentro destes órgãos com uma contrapartida extraordinária em termos de efetivação da cultura concorrencial. ${ }^{36}$

Assim, para suplantar a pouca capilaridade do sistema, pode-se aproveitar a estrutura de órgãos públicos federais para exercer competências relativas à promoção da concorrência, de modo que até mesmo o CADE possa compartilhar esta estrutura para investigações e ações educativas. Nessa senda, uma ideia interessante seria, por uma questão de aproveitamento de recursos nessas localidades, reunir, tematicamente, questões concorrenciais e aquelas relativas à combate à corrupção em articulação com os respectivos órgãos competentes, até porque, invariavelmente, as práticas locais estão ligadas a cartéis em compras públicas que, como vimos, costumam estar associadas à corrupção. ${ }^{37}$ A própria AGU teria capacidade para postular em nome da União questões concorrenciais como, aliás, já vem fazendo, especialmente, nos casos que envolvem, como já referido, a Operação Lava Jato. Além disso, o MPF e os Ministérios Públicos estaduais poderiam assumir, mais ativamente, o papel de promoção da tutela concorrencial. Dessa forma, o combate a condutas anticompetitivas associadas às práticas de desvio de dinheiro público, sobrepreço e superfaturamento em compras e obras públicas poderiam embasar uma atuação promocional que se estenderia aos demais ilícitos dos agentes privados.

Condutas e vícios frequentes das organizações públicas e privadas com potenciais impactos negativos na competição podem ser parametrizados de sorte a facilitar a difusão da concorrência por meio de normas conjuntas de atuação. Isto permitiria a supervisão e acompanhamento de eventuais desvios competitivos pelos órgãos competentes (Ministério Público, Poder Judiciário, Advocacia Pública, Tribunais de Contas, órgãos internos de controle

\footnotetext{
${ }^{36}$ Para Bork, "field offices are located in a few major cities, and their staffs tend not to work at any distance from their bases. One way to compensate for this deficiency is to give antitruste enforcement authority to states' attorneys general, but this may be a dubious solution. The attorneys general, but this may be a dubious solution. The attorneys general of many states may prove more willing to attack large out-of-state corporaions than to punish price fixing by politically important local businesses. The better solution would be to create more Antitrust Division Field offices by dispersing the personnel now concentrated in Washington." (1993: 406).

${ }^{37}$ Isto, certamente, alavancaria a discussão do tema no âmbito local.
} 
etc). No âmbito local, seria mais simples, por exemplo, adotar um plano de ação geral com base em determinadas condutas anticompetitivas que se repetem nessas realidades (v. g.: cartéis em licitação, cartéis de postos de combustível, mercado de táxis, etc).

Outra ideia a ser avaliada seria um ambicioso plano de capacitação permanente dos envolvidos na defesa e promoção da concorrência que incluiria, além de membros do SBDC, magistrados, advogados públicos membros do Ministério Público, dos Tribunais de Contas e agentes públicos atuantes no processo de formulação de políticas públicas. O já referido intercâmbio do CADE é, sem dúvida, um modelo também a ser ampliado. Mas talvez ainda mais efetivo seria a aproximação e maior articulação sistêmica com órgãos que podem fazer muito mais pela defesa e promoção da concorrência no Brasil, como já referido, Judiciário, Ministério Público, advocacias públicas, Tribunais de Contas, instituições de ensino etc

No âmbito acadêmico, em razão da dificuldade até de convencimento quanto à relevância do princípio da livre concorrência para o desenvolvimento e para a democracia, a temática antitruste poderia ser enfeixada em uma disciplina mais geral e básica que englobe temas correlatos como corrupção e conceitos básicos de direito e desenvolvimento. Nos cursos de Economia e Administração, a temática concorrencial pode ser associada com temas relacionados à inovação e competitividade, além daqueles nos quais já seria, indiretamente, trabalhada (microeconomia, organização industrial, teoria dos jogos, economia política etc).

Considerando a inexistência de fronteiras entre mercados é impossível imaginar também uma atuação que se revele efetiva sem que exista mínima coordenação no âmbito supranacional para formular novos padrões para o antitruste e para implementação da advocacy. Nesse sentido, a aproximação do SBDC com órgãos como ICN, OCDE, UNCTAD e Banco Mundial, como, de resto, já vem sendo empreendida, é de fundamental importância para promoção da concorrência (RODAS, 2016).

Com intuito de facilitar a reflexão e debate sobre eventuais aperfeiçoamentos no sistema de defesa da concorrência, sumarizo a seguir algumas destas possíveis ideias:

1) Alteração da LDC, de modo a que esta passe a se constituir em uma autêntica Lei de Promoção e Defesa da Concorrência ${ }^{38}$, implementando-se uma visão pró-ativa de

\footnotetext{
${ }^{38}$ A prioridade da promoção da concorrência sobre as funções tradicionais de defesa da concorrência tem sido proposta por organismos internacionais (ICN, 2002: 8).
} 
competition advocacy (OLIVEIRA, 1998) e incorporando também, expressamente, como requisitos para aprovação de atos de concentração, a necessidade de que contribuam para inovação e competitividade (CORRÊA, 2009: 100) nos termos dos artigos 218 e 219 da CF;

2) Incorporação da SEAE pelo CADE com a criação de nova Divisão de Promoção da Concorrência acompanhada do aproveitamento de cargos e pessoal da Secretaria, objetivando-se valorizar a advocacy e permitir maior conjugação com ações de enforcement;

3) Alteração das respectivas Diretrizes Curriculares do MEC para que os eixos curriculares dos cursos de Direito, Economia e Administração apresentem também o tema da defesa e promoção da concorrência que, no caso do direito, pode ser previsto, conjuntamente, com a temática anticorrupção e defesa do consumidor, que, infelizmente, também ficaram de fora dos "eixos interligados de formação" ("eixo de formação fundamental", "eixo de formação profissional" e "eixo de formação prática") regulamentados pelo MEC;

4) Sugestão de Inclusão da disciplina autônoma "Direito da Concorrência" nos Exames da $\mathrm{OAB}$, concursos do Ministério Público, Magistratura e Advocacia Pública. A inclusão teria importante efeito indutor sobre a organização de estruturas curriculares de faculdades e "cursinhos", de tal forma que passem a prever a matéria concorrencial como preparação para estes exames;

5) Previsão de que recursos das decisões do CADE sejam dirigidos, diretamente, para Turma Especializada do TRF1 conforme proposta presente em obra de autoria dos Professores Juliano Souza de Albuquerque Maranhão, Paulo Furquim de Azevedo e Tércio Sampaio Ferraz Júnior (2014) e, recentemente, avalizada pela própria Justiça Federal por meio do Processo $n^{\circ}$ CJF-PPP-2016/00010;

6) Criação de uma rede de estudos em pesquisa empírica no âmbito concorrencial entre SBDC, IPEA e BNDES, até como um meio de avaliar possíveis impactos na competição de políticas de desenvolvimento, para acompanhamento concorrencial permanente de setores 
específicos e incentivo à inovação e competitividade nos termos previstos pelos artigos 218 e 219 da CF;

7) "Retorno" da regra revogada da Lei 8.884/94 (§ 3 do art. 54 da Lei 8.884/94) que previa como critério para notificação obrigatória que a operação resulte em $20 \%$ ou mais de participação de mercado (DOMINGUES e GABAN, 2012). A alteração teria importante efeito indutor de comportamentos pró-competitivos em diversos mercados não alcançados pelo controle de estruturas e até para difusão da cultura da concorrência de modo mais amplo. Além disso, para valorizar a análise com base em componente inovativo, seria importante também revogar o art. 88, II da LDC que excluiu da apreciação do CADE aquelas operações em que o outro grupo envolvido tenha registrado, no último balanço, faturamento bruto anual ou volume de negócios total no País, no ano anterior à operação, inferior a R \$ 30.000.000,00 (trinta milhões de reais), uma vez que há, atualmente, grande risco de eliminação de empresas nascentes, startups ou focadas em nichos (premium ou regionais) sem que o SBDC sequer tome conhecimento de tal fato como, de resto já demonstrado anteriormente.

8) Ampliar SBDC de modo a que consista em sistema articulado com órgãos em outras esferas. Como referido, é possível aproveitar estrutura de órgãos federais que hoje se encontram nas principais cidades do país. Pode-se pensar também em comissões de promoção da concorrência e combate à corrupção em cidades com mais de 500 mil habitantes composta por membros do MP (federal e/ou estadual), membros da advocacia pública federal e/ou estadual, com a competência de instruir processos e receber denúncias para subsidiar ações judiciais, bem como auxiliar o CADE em suas investigações como uma espécie de longa manus.

9) Previsão de que empresas que queiram participar do Novo Mercado ou que desejem contratar com o Poder Público acima de um determinado valor tenham que comprovar participação periódica em programas oficiais de Compliance na área concorrencial e anticorrupção. 
10) Criação, no âmbito antitruste, do "compliance premiado" como fator de redução da multa a exemplo do que já existe no âmbito anticorrupção conforme Decreto 8.420/2015 (GABAN e DOMINGUES, 2016:346);

11) Repensar estrutura organizacional do CADE para que Conselheiros tenham maior isenção, de modo a que sejam evitados problemas do tipo "revolving door", isto é, trocas constantes de pessoas que ocupam posições no SBDC e, em outros momentos, na iniciativa privada. Conselheiros do CADE deveriam ser dotados de garantias e prerrogativas para fortalecer a autonomia do órgão;

12) Alteração do $\S 3^{\circ}$ do art. 28 da LDC de modo que a receita oriunda de multas e acordos do CADE sejam destinadas, especificamente, para atividades educativas de promoção da concorrência em parceria com OAB, MEC e CJF;

13) Acionamento mais frequente da CCAF pelo SBDC para contestação de atos contrários à concorrência emanados de órgãos públicos federais, distritais, estaduais e municipais (GODOY, 2012). Nesse caso, o ideal seria alteração legal para que não apenas questões de conflitos de competência propriamente dito sejam solucionadas, mas possíveis atos oriundos de outros órgãos e esferas da Federação que, pela sistemática atual, não poderiam ser revistos pelo CADE e que, portanto, seriam levados ao CCAF para solução consensual. Em caso de inexistência de acordo nos casos de conflitos com órgãos de outras esferas, o CADE poderia recorrer à própria AGU para contestação judicial do ato. 


\section{BIBLIOGRAFIA}

ACEMOGLU, Daron e ROBINSON, James. Why Nations Fail - The Origins of Power, Prosperity, and Poverty. Crown Publishers, New York: 2012.

ACEMOGLU, Daron; Johnson, Simon; Robinson, James A. The Colonial Origins of Comparative Development: An Empirical Investigation. American Economic Review, 91, pp. 1369-1401, Dez. 2001.

AGHION, Phillippe; GRIFFITH, Rachel. Competition and Growth: Reconciling Theory and Evidence. Cambridge: MIT Press. 2005.

AGHION P. HOWITT, P. The Economics of Growth, MIT Press 2009 and Aghion P, Akcigit U, Howitt P. What Do We Learn From Schumpeterian Growth Theory? 2013.

AGHION, Philippe. BRAUN, Matias, FEDDERKE, Johannes. Competition and productivity growth in South Africa. Economics of Transition 16(4): 741-768. 2008.

ANDRADE, José Maria Arruda. Economicização do Direito Concorrencial e Positivismo Jurídico: Entre Teoria da Decisão e das Provas. São Paulo: Tese (Livre-Docência) Faculdade de Direito da USP, Universidade de São Paulo, São Paulo, 2012.

ARAUJO JR., José Tavares de. Antitruste e advocacia da concorrencia: perspectivas do Sistema Brasileiro de Defesa da Concorrencia à luz da experiencia australiana.

Publicações do BNDES, 2014. Disponível em: <http://www.bndes.gov.br/bibliotecadigital>. Acesso em 18/03/2017.

ÁVILA, Humberto. Teoria da Igualdade Tributária. São Paulo. Malheiros Editores, 2008.

A Distinção entre Princípios e Regras e a Redefinição do Dever de Proporcionalidade. R. Dir. Adm., Rio de Janeiro, 215: 151-179, jan. /mar. 1999.

ARNAUD, André-Jean. O Direito Entre Modernidade e Globalização: lições de filosofia do Direito e do Estado. Front Cover. André-Jean Arnaud. Rio de Janeiro: Renovar, 1999.

ARNAUD, André-Jean e JUNQUEIRA, Eliane Botelho (orgs), Dicionário da Globalização. Direito, Ciência Política, Rio de Janeiro, Editora Lumen Juris, 2006.

ASSIS, Jesus de Paula. Kuhn e as Ciências Sociais: in Estud. av. [online]. 1993, vol.7, n.19, pp.133-164. ISSN 0103-4014. Disponível em Scielo: <http://dx.doi.org/10.1590/S010340141993000300004>. Acesso em 18/02/2017.

BAKER, Jonathan B., Beyond Schumpeter vs. Arrow: How Antitrust Fosters Innovation (June 1, 2007). Antitrust Law Journal, Vol. 74, 2007. Disponível em SSRN: $<$ http://ssrn.com/abstract=962261 > or <http://dx.doi.org/10.2139/ssrn.962261>. Acesso em 07/08/2015. 
BAKER, Jonathan. SALOP, Steven. Antitrust, Competition Policy, and Inequality (2015). Working Papers. Paper 41. Disponível em:

<http://digitalcommons.wcl.american.edu/fac_works_papers/41>. Acesso em 20/12/2015.

BALKIN, Jack M. Too Good to Be True: The Positive Economic Theory of Law. (1987).

Faculty Scholarship Series. Paper 290. Disponível em

http://digitalcommons.law.yale.edu/fss_papers/290. Acesso em 18/02/2017.

BANCO MUNDIAL. Transforming markets through competition: new developments and recent trends in competition advocacy. 2016. Disponível em:

<http://documents.worldbank.org/curated/pt/640191467990945906/pdf/104806-REPF-

Transforming-Markets-Through-Competition.pdf>. Acesso em 23/12/2016.

BARTH, James R., CAPRIO Jr., Gerald; ROSS, Levine. Rethinking Bank Regulation - Till Angels Govern. New York: Cambridge. 2006.

BECK, Ulrich. La Sociedad Del Riesgo. Barcelona: Paidós, 1998.

BHAGWATI, Jagdish N. Democracy and Development: Cruel Dilemma or Symbiotic Relationship? Review of Development Economics; v. 6, n. 2, Jun/2002.

BINENBOJM, Gustavo. Meios de comunicação de massa, pluralismo e democracia deliberativa. As liberdades de expressão e de imprensa nos Estados Unidos e no Brasil. Revista Eletrônica de Direito Administrativo Econômico. Salvador, nº. 5, fev/mar/abr, 2006.

BOBBIO, Norberto. Da estrutura à função: novos estudos da teoria do direito. Barueri: Manole, 2007.

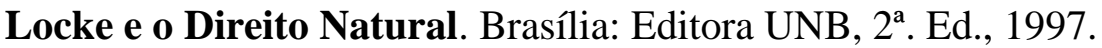

O Marxismo e o Estado. Rio de Janeiro: Editora Graal. 2ª Ed., 1991.

BORK. The Antitrust Paradox: a Policy at War with Itself. New York: The Free Press, $2^{\mathrm{a}}$. ed., 1993.

363-76.

BOWMAN, W. S. The Crisis in Antitrust. Columbia Law Rev., March 1965, 65,

BORTOLOZZI, Madian Luana. Verbete "Soft Law". In: ARNAUD, André-Jean e JUNQUEIRA, Eliane Botelho (orgs), Dicionário da Globalização (pp. 422-423). Direito, Ciência Política, Rio de Janeiro, Editora Lumen Juris, 2006.

BOURDIEU, Pierre. Homo Academicus. Madrid: Siglo XXI, 2008.

BOVINO, Alberto; COURTIS, Christian. 2000. Por una dogmática conscientemente política, Anuario de filosofía del derecho, № ${ }^{\circ}$ 17, Madrid. Crelier, Andrés. 2012.

BRENNAN, Timothy J. (2008) Essential Facilities and Trinko: Should Antitrust and Regulation Be Combined?. Federal Communications Law Journal: Vol. 61: Iss. 1, Article 9. 
2009 Available at: http://www.repository.law.indiana.edu/fclj/vol61/iss1/9> Acesso em: 12/04/2017.

BRASIL. Ministério da Fazenda. Julho de 2017. Sancionada lei que cria Taxa de Longo Prazo (TLP) em substituição à TJLP. Disponível em: http://fazenda.gov.br/noticias/2017/julho/sancionada-lei-que-cria-taxa-de-longo-prazo-tlp-emsubstituicao-a-tjlp Acesso em 13/12/2017.

BRELÁZ, Gabriela de. Advocacy das Organizações da Sociedade Civil: Principais Descobertas de um Estudo Comparativo entre Brasil e Estados Unidos. Setembro de 2007. Disponível em <http://www.anpad.org.br/admin/pdf/APS-A1916.pdf> Acesso em 13/12/2016.

BRETTEL, Malte, FRIEDERICHSEN, Niklas, KELLER, Michael; ROSENBERG, Marius. How Virtualization, Decentralization and Network Building Change the Manufacturing Landscape: An Industry 4.0 Perspective. World Academy of Science, Engineering and Technology International Journal of Information and Communication Engineering Vol:8, No:1, 2014. Disponível em: http://www.waset.org/publications/9997144 Acesso em 13/12/2016.

BRZOWSKI, Marcos Vinicius. Economia como Processo Complexo: A Crítica De Hayek Aos Economistas Neoclássicos. Dissertação de Mestrado do Programa de Pós-Graduação em Filosofia da Universidade Federal do Paraná, Curitiba, 2014.

BUCCIROSSI, Paolo Lorenzo Ciari. DUSO, Tomaso. SPAGNOLO, Giancarlo. VITALE, Cristiana. Competition Policy and Productivity Growth: An Empirical Assessment. In: The Review of Economics and Statistics, October 2013, 95(4): 1324-1336. BUSINESS INSIDER, "2016 hopeful Bernie Sanders: If a bank is too big to fail, 'it's too big to exist"' <http://www.businessinsider.com/r-us-presidential-hopeful-sanders-break-up-thebig-banks-2015-5>, 5/05/2015. Acesso em 18/02/2017.

BUSINESS INSIDER, "Blockbuster's CEO once passed up a chance to buy Netflix for only \$50 million”, Jul. 17, 2015, Disponível em: <http://www.businessinsider.com/blockbusterceo-passed-up-chance-to-buy-netflix-for-50-million-2015-7> Acesso em 05/04/2017.

CABRAL, Mário André Machado. Primeiro passo na política antitruste brasileira, Lei Malaia completa 70 anos.In Revista Consultor Jurídico. 12/122015. Disponível em: <http://www.conjur.com.br/2015-dez-12/mario-cabral-primeira-antitruste-lei-malaiacompleta-70-anos>. Acesso em 07/07/2016.

CADE: Conselho Administrativo de Defesa Econômica. Departamento de Estudos Econômicos (DEE). Documento de Trabalho No. 001/10. Brasília, Novembro de 2010. Disponível em: <http://www.cade.gov.br/acesso-a-informacao/publicacoes-institucionais/deepublicacoes-anexos/delimitacao_de_mercado_relevante.pdf> Acesso em 05/04/2017.

Mercado de Saúde Suplementar: Condutas. 2015.

http://en.cade.gov.br/topics/about-us/dee/arquivos/cadernos-do-cade-2013-mercado-de-saudesuplementar-condutas-2013-2015.pdf

Relatório de Gestão do Exercício de 2015, Brasília, Março de 2016.

Disponível em: <http://www.cade.gov.br/acesso-a-informacao/auditorias-1/auditoriasanexos/2015/relatorio-de-gestao-2015-final.pdf>. Acesso em 05/04/2017. 
Guia para Análise de Atos de Concentração Horizontal (GUIA H), Julho de 2016. Disponível em: < http://www.cade.gov.br/acesso-a-informacao/publicacoesinstitucionais/guias_do_Cade/guia-para-analise-de-atos-de-concentracao-horizontal.pdf> Acesso em 05/04/2017.

CAMPILONGO, Celso Fernandes. O Direito na Sociedade Complexa. São Paulo: Max Limonad, 2000.

Tributos, Liminares e Concorrência. São Paulo, Valor Econômico, 23 de fev. 2006.

CANADÁ. Competition Bureau, 2015. Disponível em:

http://www.competitionbureau.gc.ca/eic/site/cb-bc.nsf/eng/03897.html Acesso em 07/08/2017

CANADÁ. Competition Bureau, 2016. Disponível em: https://www.ic.gc.ca/eic/site/aeve.nsf/eng/h_03856.html Acesso em 07/08/2017

CANADÁ. Competition Bureau, 2017a. Disponível em:

https://www.canada.ca/en/competition-

bureau/news/2017/05/the_borderless_digitaleconomywhatconsumersandbusinessesneedtokno. html? wbdisable=true Acesso em 07/08/2017

CANADÁ. Competition Bureau, 2017b. Disponível em:

https://www.canada.ca/en/competition-

bureau/news/2017/03/promoting_competitioninnovationandgrowthinsaskatchewanandallofca. html? wbdisable=true Acesso em 07/08/2017

CANADÁ. Competition Bureau, 2017c. Evaluation of the Competition Bureau's Advocacy Function, Junho de 2016, Presented to the Performance Measurement and Evaluation Committee on February 8, 2017, Approved by the Deputy Minister on May 29, 2017 Disponível em: https://www.ic.gc.ca/eic/site/ae-ve.nsf/vwapj/CB-Final-Report-2017eng.pdf/\$file/CB-Final-Report-2017-eng.pdf Acesso em 07/08/2017

CANOTILHO, José Joaquim Gomes. Direito Constitucional e Teoria da Constituição.

Coimbra: Editora Almedina. $3^{\text {a }}$. Ed. 1999.

CARVALHO, Leonardo Arquimino. O Ensino da Defesa e da Promoção da Concorrência nos Cursos de Graduação em Direito no Brasil. In: Revista de Direito Empresarial, p. 167235 Curitiba: Juruá Editora, jul-dez. 2008.

CASAGRANDE, Paulo Leonardo. Inovação, Cooperação e Concorrência: Desafios para a Política Antitruste no Brasil. 2014. Doutorado em Direito do Estado. Universidade de São Paulo, USP, Brasil.

CELLI JR., Umberto. O Direito da Concorrência no Direito Comunitário Europeu: uma Contribuição ao Mercosul. Porto Alegre: Livraria do Advogado, 1999. 
CMA. CMA recommendations to government. 2016. Disponível em:

<https://www.gov.uk/government/publications/cma-recommendations-to-government> Acesso em 01/05/2017.

COASE, Ronald H. A Firma, o Mercado e o Direito. Rio de Janeiro: Forense Universitária, 2016.

CORRÊA, Daniela Godoy Martins. Eficiências Econômicas na Análise Antitruste: Limitações dos Critérios Tradicionais e Perspectivas. Dissertação apresentada ao Curso de Mestrado do Instituto de Economia da Universidade Federal do Rio De Janeiro como requisito parcial à obtenção do título de Mestre em Economia. Rio de Janeiro, Setembro de 2009.

COUTINHO, Diogo R. Direito, desigualdade e desenvolvimento. São Paulo: Saraiva, 2013.

COUTINHO, Paulo C. . Prolegômenos da Economia da Defesa da Concorrência. Revista do IBRAC, São Paulo, SP, v. 8, n.4, p. 151-182, 2001.

CRANE, Daniel A. The Tempting of Antitrust: Robert Bork and the Goals of Antitrust Policy. Antitrust L. J. 79, no. 3 (2014): 835-53.

CUEVA, Ricardo Villas Bôas. A proteção da propriedade intelectual e a defesa da concorrência nas decisões do CADE. In: Revista do IBRAC, v. 16, n. 1, p. 121-147, 2009. CULPEPPER, Pepper D. Quiet Politics and Business Power: Corporate Control in Europe and Japan. Cambridge University, 2011.

DE LOECKER, J., EECKHOUT, J. The Rise of Market Power and the Macroeconomic Implications, 2017. Disponível em: http://www.janeeckhout.com/wpcontent/uploads/RMP.pdf Acesso em: 14/09/2014.

DE HAAN, Jakob; SIERMANN, Clemens L. J. New evidence on the relationship between democracy and economic growth. Public Choice, v. 86, n. 1-2, Janeiro, 1996. Disponível em: http://www.springerlink.com/content/n7h1706010602k58/. Acesso em: 01 jun. 2015.

DECKER, R., J. HALTIWANGER, R. JARMIN, AND J. MIRANDA: The secular decline in business dynamism in the US. University of Maryland. 2014. Disponível em: http://econweb.umd.edu/ haltiwan/DHJM_6_2_2014.pdf Acesso em: 07/08/2017.

DECKER, R., J. HALTIWANGER, R. JARMIN, AND J. MIRANDA: Where has all the skewness gone? the decline in high-growth (young) firms in the U.S. Working Papers 1543, Center for Economic Studies, U.S. Census Bureau, November 2015.

DERANI, Cristiane. Direito Ambiental Econômico. 2. ed. São Paulo: Max Limonad, 2001 DESCARTES, René. Discurso do Método. São Paulo: Martins Fontes. 2001.

DOJ. Division Update Spring 2013. Atualizado em 21 de julho de 2015. Disponível em: $<$ https://www.justice.gov/atr/public-documents/division-update-spring-2013/competitionadvocacy> Acesso em 01/05/2017. 
Competition Guidance and Advocacy 2017 (Division Update Spring 2017). 2017. Disponível em: <https://www.justice.gov/atr/division-operations/division-update-spring2017/competition-guidance-and-advocacy-2017>. Acesso em 01/05/2017.

FTC. Antitrust Guidance For Human Resource Professionals. 2016. Disponível em: <https://www.justice.gov/atr/file/903511/download>. Acesso em 01/05/2017.

. Antitrust Guidance For The Licensing of Intellectual Property. 2017. Disponível em: https://www.justice.gov/atr/IPguidelines/download DOMINGUES, Juliana Oliveira. Comentários ao artigo 36, incisos I a IV e $\$ \mathbf{1}^{\circ}$ e $3^{\circ}$. In: ANDERS, Eduardo Caminati; PAGOTTO, Leopoldo. BAGNOLI, Vicente. Comentários à nova lei de defesa da concorrência. Rio de Janeiro: Forense, 2012.

GABAN, Eduardo Molan. Direito antitruste. 3.ed. São Paulo: Saraiva, 2012.

Direito antitruste. 4.ed. São Paulo: Saraiva, 2016.

Instituições, Livre Concorrência e o CADE: Inspiração ao

Desenvolvimento da América Latina. In: Instituciones y desarollo en la hora actual de America Latina, 2016, Montevideu. V Encontro Internacional do CONPEDI Montevidéu, Uruguai. Florianópolis: CONPEDI, 2016. p. 105-121.

. Nova lei permitirá a criação de monopólios. Folha de São Paulo,

Opinião, 08 jul./2012. Disponível em: <http://www1.folha.uol.com.br/fsp/opiniao/53304nova-lei-permitira-a-criacao-demonopolios.shtml>. Acesso em: 06.11.2016.

. LOCHAGIN, Gabriel L. A. A ZFM e os princípios da OMC: o Processo Produtivo

Básico visto como um política necessária ao desenvolvimento regional In:

DESIGUALDADES E DESENVOLVIMENTO: O papel do Direito nas políticas públicas", 2017, Brasilia. XXVII Encontro do CONPEDI. Florianópolis: CONPEDI, 2017.

DOTTLING, Robbin.; GUTIÉRREZ, German e PHILIPPON, Thomas. Is there an investment gap in advanced economies? If so, why? 2017. Disponível em:

https://www.ecbforum.eu/uploads/originals/2017/speakers/papers/T_Philippon_Is_there_an_i nvestment_gap_in_advanced_economies_If_so_why_with_R_Dottling_and_G_Gutierrez.pdf Acesso em: 14/09/2017.

EMBRAER. Embraer lands in the Silicon Valley, with sights on disruptive innovation.

2017. Disponível em: <http://www.embraer.com/en-US/ImprensaEventos/Pressreleases/noticias/Pages/Embraer-lands-in-the-Silicon-Valley,-with-sights-on-disruptiveinnovation.aspx>. Acesso em 25/04/2017.

EXAME. “O que fazer com as cervejas 'artesanais', Lemman?”, 18/05/2016. Disponível em: $<$ http://exame.abril.com.br/blog/branding-consumo-negocios/o-que-fazer-com-as-cervejasartesanais-lemman/> Acesso em 25/04/2017.

FAGUNDES, J.; NISHIJIMA, Marislei; LIMA, M.; Lagroteria, E.; Rocha, M.M. Sobre a determinação de mercados relevantes: teste de elasticidade crítica e teste de perda crítica. 2010. Revista do IBRAC Suplemento Eletrônico, n² 
FAGUNDES, J. Concorrência, Eficiência Dinâmica e Análise Antitruste. In: Revista do IBRAC, volume 11, número 4, 2004.

FAGUNDES, J. Políticas de Defesa da Concorrência e Política Industrial: Convergência ou Divergência? In: Revista do IBRAC, volume 5, número 6, 1998.

FERRAZ, Ana Paula do Carmo Marcheti. BELHOT, Renato Vairo. Gest. Prod., São Carlos, v. 17, n. 2, p. 421-431, 2010. Disponível em <http://www.scielo.br/pdf/gp/v17n2/a15v17n2> Acesso em: 04-08-2015.

FERRAZ, Roberto. A inversão do princípio da capacidade contributiva no aumento da Cofins pela Lei 9.718. Revista Dialética de Direito Tributário, S.P., Ed. Oliveira Rocha, v. 130 , jul de 2006.

FLYNN, John J. Antitrust policy and the concept of a competitive process. New York Law School Review, New York, v. 35, n. 4, p. 893-916, 1990.

FOER, Albert. The Third Leg of the Antitrust Stool: What the Business Schools Have to Offer to Antitrust, in 47 N.Y.L. SCH. L. REV. 21 (2003).

FOX, Eleanor M., Antitrust and Institutions: Design and Change, 41 Loy. U. Chi. L. J. 473 (2010). Disponível em: <http://lawecommons.luc.edu/luclj/vol41/iss3/6>

FOX, Eleanor M., The Efficiency Paradox (July 8, 2009). How the Chicago School overshot the mark: the effect of conservative economic analysis on U.S. ANTITRUST, R. Pitofsky, ed., Oxford, p. 77, 2008; NYU Law and Economics Research Paper No. 09-26. Disponível em SSRN: <https://ssrn.com/abstract=1431558>

FORGIONI, Paula A. Os Fundamentos do Antitruste. São Paulo, Editora RT, 1998.

FREITAS DE OLIVEIRA, Raul Miguel Freitas de. Concessão Florestal: exploração sustentável de florestas públicas por particular, Ano de obtenção: 2010. Doutorado em Direito do Estado. Universidade de São Paulo, USP, Brasil. Disponível em:

<http://www.teses.usp.br/teses/disponiveis/2/2134/tde-18112010-135806/pt-br.php>. Acesso em 10 de nov. 2015.

FREITAS MARTINS, Ana Gouveia e. O Princípio da Precaução no Direito do Ambiente. Lisboa: Associação Acadêmica da Faculdade de Direito de Lisboa, 2002.

FRIEDMAN, Milton. Capitalism and Freedom. Chicago: University of Chicago Press. 1962. Disponível em <https://www.pdf-archive.com/2011/12/28/friedman-milton-capitalismand-freedom/friedman-milton-capitalism-and-freedom.pdf $>$

The Methodology of Positive Economics. In: Essays In Positive Economics (Chicago: Univ. of Chicago Press, 1966), pp. 3-16, 30-43.

There's No Such Thing as a Free Lunch. Chicago: Open Court Pub, 1975.

GALA, Paulo. A Teoria Institucional de Douglass North. Revista de Economia Política, vol. 23, no 2 (90), abril-junho/2003. 
GELLHORN, Ernest \& KOVACIC, William E. Antitrust Law and Economics in a Nutshell. St. Paul: West Group, 1994.

GERADIN, Damien. Antitrust Compliance Programmes \& Optimal Antitrust

Enforcement: A Reply to Wouter Wils (March 29, 2013). Journal of Antitrust Enforcement (2013) (Forthcoming). Disponível em SSRN: https://ssrn.com/abstract=2241452

GEROSKI, Paul. Competition Policy and National Champions. In: "Essays in Competition Policy", UK Competition Commission, 2005, pp. 37-42, disponível em https://www.regulation.org.uk/library/2006_geroski_essays.pdf Acesso em 13/12/2016.

GIL, Antonio Carlos. Métodos e Técnicas de Pesquisa Social. 6a . Edição. São Paulo. Editora Atlas. 2012.

GODOY, Arnaldo Sampaio de Moraes. Domesticando o Leviatã: Litigância Intragovernamental e Presidencialismo de Articulação Institucional. Tese de Livre Docência. Faculdade de Direito. USP. São Paulo, 2012.

GOMES, Nelson Gonçalves. Um Panorama da Lógica Deôntica. Kriterion, Belo Horizonte, v. 49, n. 117, p. 9-38, 2008. Disponível em:

$<$ http://www.scielo.br/scielo.php?script=sci_arttext\&pid=S0100-

512X2008000100002\&lng=en\&nrm=iso>. Acesso em 20 de fevereiro de 2017.

GOMEZ, R.; GOEREE, J.; HOLT, C. A. Predatory Pricing: Rare Like a Unicorn? Virginia Economics Online Papers 339, University of Virginia, Department of Economics, 1999.

Disponível em:<http://www.virginia.edu/economics/RePEc/vir/virpap/papers/virpap339.pdf> Acesso em 02/04/2017.

GRAU, Eros Roberto. O Direito Posto e o Direito Pressuposto. $7^{\text {a }}$. ed. São Paulo: Malheiros, 2008.

GREENE, Brian. EI Universo Elegante. Supercuerdas, Dimensiones Ocultas y la Búsqueda de uma Teoria Final. Barcelona: Drakontos. 2006.

GRULLON, G.; LARKIN, Y.; MICHAELY, R.. Are us industries becoming more concentrated. 31/08/2017. Disponível em SSRN: https://ssrn.com/abstract=2612047 ou http://dx.doi.org/10.2139/ssrn.26120472017. Acesso em 14/09/2017.

GUNNINGHAM, N., \& SINCLAIR, D. (1999). Designing smart regulation. Disponível em: http://www.oecd.org/dataoecd/18/39/33947759.pdf Acesso em 01/05/2017.

GUEST, Stephen. Ronald Dworkin. Tradução de Carlos Borges. Revisão técnica de Rafael Mafei Rabelo Queiroz. Rio de Janeiro: Elsevier.2010. (Coleção Teoria e Filosofia do Direito). Imprenta: Rio de Janeiro, Campus, 2010.

GUSTIN, Miracy Barbosa de Sousa; DIAS, Maria Tereza Fonseca. (Re) Pensando a pesquisa jurídica: teoria e prática. $2^{\mathrm{a}}$ ed. Belo Horizonte: Del Rey, 2006. 
GUTIÉRREZ, Gérman; PHILIPPON, Thomas. Investmentless Growth: An Empirical Investigation. BPEA Conference Drafts 7-8/09/2017. Disponível em: https://www.brookings.edu/wp-content/uploads/2017/09/2_gutierrezphilippon.pdf Acesso em $14 / 09 / 2017$.

HABERMAS, Jürgen Modernity's Consciousness of Time and Its Need for Self-Reassurance, 1985, Cambridge, MA: MIT Press, 1998.

HABERMAS, Jürgen. Direito e democracia: entre facticidade e validade. Tradução de Flávio Beno Siebeneichler. 2.ed. Rio de Janeiro: Tempo Brasileiro, 2003, v. 1.

HALL, Peter A. e SOSKICE, David. Varieties of Capitalism - LSE: The Institutional Foundations of Comparative Advantage. Oxford: Oxford Scholarship Online. 2001.

HAYEK, Friedrich. Individualism and Economic Order. Chicago: The University of Chicago Press, 1946.

HAWKER, Norman W. Antitrust Insights From Strategic Management. In: Foreword: Antitrust as Public Interest Law (p. 767), PERITZ, Rudolph J. R. New York Law School Review, v. 35, no. 4, 1990.

Antitrust Insights from Strategic Management. In: New York Law School Review, REV. 67, 74 v. 47, no. 1, 2003.

HENRIQUES Miguel Gorjão; CUNHA, Carolina. Lei da Concorrência - Comentário Conimbricense. Miguel Gorjão-Henriques (dir.) Almedina, 2013.

HEISENBERG, Werner. Ist eine deterministische Erg“anzung der Quantenmechanik m oglich?. 1935. Tradução de Guido Bacciagaluppi and Elise Crull, 2011. Disponível em: <http://philsciarchive.pitt.edu/8590/1/Heis1935_EPR_Final_translation.pdf > Acesso em 20 de fevereiro de 2017.

HOFSTADTER, Richard. The Paranoid Style in American Politics. New York: Vintage Books. 2008.

HOHER, Angel Lopez. Competition Advocacy in Mexico: Lessons From the Past Decade. August 28, 2012. Disponível em: <https://www.competitionpolicyinternational.com/competition-advocacyin-mexico-lessons-from-the-past-decade> Acesso em: 05 nov. 2015.

HOVENKAMP, Herbert. Federal Antitrust Policy. The Law of Competition and its Practice, West Group, 2a ed. 1999.

ICN - International Competition Network. Report and Summary of the Presentations of the 2009-2010 ICN Competition Advocacy Teleseminars in ICN Competition Advocacy Working Group Sub-Group 1: Experience Sharing Project Presented at the 9th Annual Conference of the ICN Istanbul, April 27-29, 2010. Disponível em:

<http://www.internationalcompetitionnetwork.org/uploads/library/doc633.pdf> Acesso em: 05 nov. 2015.

ICN - Advocacy and Competition Policy. Report prepared by the Advocacy Working Group 
ICN's Conference Naples, Italy, 2002.

ICN, Economic Growth and Productivity, 2009. Disponível em:

$<$ http://www.internationalcompetitionnetwork.org/working-

groups/current/advocacy/benefits/messages/productivity.aspx>. Acesso em 10 de nov. 2015.

IPEA. Instituto de Pesquisa Econômica Aplicada. Avanços e desafios da transversalidade nas políticas públicas federais voltadas para minorias. In: Brasil em Desenvolvimento: Estado, planejamento e políticas públicas, vol 3. p. 779-795.

IPEA, Brasil em Desenvolvimento. Estado Planejamento e Políticas Públicas. 2009. Disponível em: http://www.ipea.gov.br/portal/images/stories/Livro_BrasilDesenvEN_Vol03.pdf. Acesso em 26 nov 2016.

IPEA. Desindustrialização no Brasil: Apontamentos para um Debate em Favor do Desenvolvimento Econômico Disponível, $2012 . \quad$ em: http://www.ipea.gov.br/agencia/images/stories/PDFs/conjuntura_em_foco/120315_conjuntura emfoco_marco.pdf Acesso em 26 nov 2016.

JORDÃO, Eduardo Ferreira. Limites constitucionais às restrições legislativas da concorrência. Revista Eletrônica de Direito Administrativo Econômico (REDAE), Salvador, Instituto Brasileiro de Direito Público, $\mathrm{n}^{\circ} .26$ maio/junho/julho, 2011. Disponível na Internet: <http://www.direitodoestado.com/revista/REDAE-26-MAIO-2011-EDUARDOJORDAO.pdf $>$. Acesso em: 05 nov. 2015.

KAFKA, Franz. O Castelo. São Paulo: Companhia das Letras, 2a. edição, 2000.

KANT DE LIMA, Roberto. A antropologia da academia: quando os índios somos nós. Petrópolis: Vozes; Niterói: UFF, 1985.

KAPLOW, Louis. Market Definition (May 15, 2013). Forthcoming in The Oxford Handbook of International Antitrust Economics (Roger D. Blair \& D. Daniel Sokol, ed., 2013). Disponível em SSRN: https://ssrn.com/abstract=2265304 or http://dx.doi.org/10.2139/ssrn.2265304

KAPP, William K. The Social Costs of Private Enterprise. Cambridge: Harvard University Press, 1950.

KIRKWOOD, John B. The Essence of Antitrust: Protecting Consumers and Small Suppliers from Anticompetitive Conduct, 81 Fordham L. Rev. 2425 (2013). Disponível em: $<$ http://ir.lawnet.fordham.edu/flr/vol81/iss5/10> Acesso em 29/04/2017.

KNYAZEVA, Irina. Competition Advocacy: Soft Power in Competitive Policy. In: Procedia Economics and Finance. Elsevier. 2013.

KOVACIC, William E. Assessing the Quality of Competition Policy: The Case of Horizontal Merger Enforcement5 Competition Policy International 129 (2009). Disponível 
em https://www.ftc.gov/public-statements/2009/04/assessing-quality-competition-policycase-horizontal-merger-enforcement Acesso em 26/04/2017.

KWOKA, John. Mergers, Merger Control, and Remedies: A Retrospective Analysis of U.S. Policy, Cambridge: MIT Press, 2015.

KYMLICKA, Will. Contemporary Political Philosophy: an introduction. Oxford: University Press, 2002.

KUHN, T. S. (1970a). The Structure of Scientific Revolutions. 2nd. ed. Chicago, University of Chicago Press.

LANDES, David. The Wealth and Poverty of Nations. S. W. W. Norton \& Company. New York-Londom. 1998.

LAVILLE, Christian; DIONNE, Jean. A Construção do saber - manual de metodologia da pesquisa em ciências humanas. Porto Alegre: Artes Médicas Sul Ltda; Belo Horizonte: UFMG, 1999.

LAZZARINI, Sérgio. Capitalismo de Laços: Os Donos do Brasil e suas Conexões. Editora: ELSEVIER EDITORA; Edição: 1; Ano: 2010.

LESLIE, Christopher R. Predatory Pricing and Recoupment. In: Columbia Law Review, Vol. 113, No. 7 (NOVEMBER 2013), pp. 1695-1771 Published by: Columbia Law Review Association, Inc. Disponível em: <http://www.jstor.org/stable/23561380> Acesso em 03-042017.

LIGO (Laser Interferometer Gravitational - Wave Observatory). 2017. Disponível em <https://www.ligo.caltech.edu> Acesso em 11/03/2017.

LIMA, Luiz A. de Oliveira. A Integração Micro Macroeconomia - Modelos E Justificativas. FGV/SP. Relatório de Pesquisa No 17/2005. Disponível em: <http://gvpesquisa.fgv.br/sites/gvpesquisa.fgv.br/files/publicacoes/P00329_1.pdf >. Acesso em $11 / 03 / 2017$.

LIMA Ricardo Seibel de Freitas. Livre Concorrência e o Dever de Neutralidade

Tributária. 2005. Disponível em: <http://hdl.handle.net/10183/5221>. Acesso em 19 de Mar. 2016.

LUCRETIUS, T. C., De Rerum Natura, 100 a.c. Disponível em:

<https://www.loebclassics.com/view/lucretius-de_rerum_natura/1924/pb_LCL181.113.xml> Acesso em 9 de março de 2017.

MACEDO JUNIOR, Ronaldo Porto. Posner e a Análise Econômica Do Direito: Da Rigidez Neoclássica Ao Pragmatismo Frouxo. In: Maria Lucia L M Padua Lima. (Org.). Direito E Economia 30 Anos De Brasil - Tomo 1. $1^{a}$ ed.São Paulo: Editora Saraiva, 2012, V. 1, P. 260281.

MAGALHÃES, Agamenon. A Industria Nacional e os Trusts. Folha da Manhã e Rádio Clube de Pernambuco: Diários Associados. Recife, 26/04/44 (Arq. AGM c 1944.04.26). 
Disponível em: http://www.fgv.br/cpdoc/guia/detalhesfundo.aspx?sigla=AGM Acesso em: 10/05/2016.

MANKIW, Greg. Al Gore in the Pigou Club. 24 de junho de 2006. Disponível em: http://gregmankiw.blogspot.com.br/2006/06/al-gore-in-pigou-club.html Acesso em: 10/05/2017.

MARANHÃO, J. S. A. et. al. Direito Regulatório e Concorrencial, no Poder Judiciário. 1. ed. São Paulo: Singular, 2014. v. 1. 289p

MARRARA, Thiago. A Conformação do Direito Administrativo da Concorrência: Organização, Processos e Acordos Administrativos no SBDC. Tese (Livre-Docência) Faculdade de Direito da USP, Universidade de São Paulo, São Paulo, 2014.

Defesa da concorrência x regulação setorial: o que mudou com a lei de 2011 ? Revista de Direito Público da Economia - RDPE, Belo Horizonte, ano 13, n. 50, p. 245-261, abr./jun. 2015.

. O Princípio da Publicidade: uma Proposta de Renovação. In: Princípios de Direito Administrativo. Editora Atlas S.A. 2012.

. Sistema Brasileiro de Defesa da Concorrência: organização, processos e acordos administrativos. São Paulo: Atlas, 2015.

MARQUES NETO, Agostinho Ramalho. A Ciência do Direito. Rio de Janeiro: Renovar, $2^{\text {a }}$ edição, 2001.

MARQUES NETO, Floriano de Azevedo. FREITAS, Rafael Véras de. Uber, WhatsApp, Netflix: os novos quadrantes da publicatio e da assimetria regulatória. In: R. de Dir. Público da Economia - RDPE, Belo Horizonte: Fórum, ano 14, n. 56, p. 75-108, out./dez. 2016.

MAZZUCATO, Mariana. O Estado empreendedor. São Paulo: Portfolio Penguin, 2014.

MCCLOSKEY, Deirdre N. Bourgeois Dignity: Why Economics Can't Explain the Modern World. Chicago: University of Chicago Press. 2010.

MENDES, Guilherme Adolfo dos Santos, Extrafiscalidade: análise semiótica. Tese de doutorado em Direito. Ano de Obtenção: 2009. Disponível em www.teses.usp.br/teses/disponiveis/2/2133/tde-18112009-090938/

MIRA, Elson Cedro. O Desenvolvimento Econômico Além do Mainstream: Institucionalismo e Outras Perspectivas (IPEA). Disponível em: <www.ipea.gov.br/code2011/chamada2011/pdf/area4/area4-artigo15.pdf $\geq$

MONTEIRO, Jorge Vianna. Lições de Economia Constitucional Brasileira. Rio de Janeiro: FGV Editora. 2004.

MORAIS, L. D. S. Direito da Concorrência: Perspectivas do seu Ensino. Coimbra: Almedina. 2009. 
MOREIRA, Vital. A Auto-Regulação Profissional e Administração Pública. Coimbra, Almedina, 1997.

MURRISA Terry. Materials of the First international competition network. Naples, September, 2002.

MUSACCHIO, Aldo; LAZZARINI, Sérgio. Reinventando o capitalismo de Estado. O Leviatã nos negócios: Brasil e outros países. São Paulo: Portfolio-Penguin, 2015.

NAKANE, Márcio I. Concorrência e spread bancário: uma revisão da evidência no Brasil. Relatório de Economia Bancária e Crédito. Dezembro de 2003. Banco Central do Brasil. Disponível em: <http://www.bcb.gov.br/?SPREAD>. Acesso em: 29 jun. 2016.

NELSON, Richard R; WINTER Sidney G., An Evolutionary Theory of Economic Change. Cambridge: Harvard University Press, 1982.

NICKELL, Stephen J. Competition and Corporate Performance. Journal of Political Economy. Vol. 104, No. 4 (Aug., 1996), pp. 724-746 . See also Michael E. Porter, The Competitive Advantage of Nations (1990), at 662.

NORSEN, Travis. Foundations of Quantum Mechanics. An Exploration of the Physical Meaning of Quantum Theory. New York: Springer. 2017.

NORTH, Douglass. Institutional Change and Economic Growth. The Journal of Economic History, Vol. 31, No. 1, The Tasks of Economic History (Mar., 1971), pp. 118-125. Cambridge University Press Economic History Association Stable URL: http://www.jstor.org/stable/2117023 Acesso em: 04-08-201.

. DAVIS, Lance. Institutional Change and American Economic Growth. The Journal of Economic History, Vol. 30, No. 1, The Tasks of Economic History (Mar., 1970), pp. 131-149. Cambridge University Press Economic History Association Stable URL:<http://www.jstor.org/stable/2116728> Acesso em: 04-08-2015.

Institutions. The Journal of Economic Perspectives, Vol. 5, No. 1 (Winter, 1991), pp. 97-112. American Economic Association. Stable URL: http://www.jstor.org/stable/1942704. Accesso em: 04-08-2015

. MANTZAVINOS, Chris. SHARIQ, Syed. Learning, Institutions, and Economic Performance. Perspectives on Politics, Vol. 2, No. 1, 2004. Available at SSRN: http://ssrn.com/abstract=510902 Acesso em: 04-08-2015.

WALLIS, John Joseph, WEBB, Steven B. e WEINGAST, Barry R. Limited Access Orders in the Developing World. A New Approach to the Problems of Development. The World Bank. Independent Evaluation Group. Country Relations Division. September 2007.

. FOGEL, Robert W. Nobel Lectures, Economics 1991-1995, Editor Torsten Persson, World Scientific Publishing Co., Singapore, 1997. Disponível em: <http://lawecommons.luc.edu/luclj/vol41/iss3/6>. 
OCDE. Big Data: Bringing Competition Policy to the Digital Era -- Background note by the Secretariat -- 29-30 November 2016

<https://one.oecd.org/document/DAF/COMP(2016)14/en/pdf>

. Competition Advocacy: Challenges for Developing Countries", Washington

14-15 June 2004. Disponível em:

<https://www.oecd.org/competition/latinamerica/2004\%20Latin\%20American\%20Competiti on\%20Forum.pdf>. Acesso em: 05 nov. 2015.

Glossary of Industrial Organisation Economics and Competition Law, compiled by R. S. Khemani and D. M. Shapiro, commissioned by the Directorate for Financial, Fiscal and Enterprise Affairs, OECD, 1993. Disponível em: <http://www.oecd.org/regreform/sectors/2376087.pdf>. Acesso em: 20-03-2017.

. Guidelines for Fighting Bid Rigging in Public Procurement. 2009.

Disponível em: <http://www.oecd.org/dataoecd/27/19/42851044.pdf>. Acesso em: 05 nov. 2015.

Facsheet on How Competition Policy Affects Macro-economic Outcomes. 2014. Disponível em: <http://www.oecd.org/daf/competition/2014-competition-factsheet-iven.pdf >. Acesso em: 20-03-2017.

OECD. The Competition Assessment Toolkit (2011). Disponível em:

<https://www.oecd.org/daf/competition/42228385.pdf> Acesso em: 20-03-2017.

. The Future Ain't What It Used to Be - 20 Years of Competition Law and the Challenges Ahead. 2013. Disponível em: <http://www.oecd.org/tax/20-years-of-competitionlaw-and-the-challenges-ahead.htm> Acesso em: 05 nov. 2015.

OCKÉ-REIS, C. O.; ANDREAZZI, M.F.S e SILVEIRA, F.G. O Mercado de Planos de Saúde no Brasil: uma Criação do Estado. R. Econom. Contemporânea, 157-185. Rio de Janeiro, Jan-Abr de 2006. Disponível em: 〈http://www.scielo.br/pdf/rec/v10n1/07.pdf> Acesso em: 05 nov. 2015.

OFT. Evaluation of OFT Competition Advocacy. Disponível em: $<$ https://londoneconomics.co.uk/wp-content/uploads/2011/09/21-Evaluation-of-OFTCompetition-Advocacy.pdf $>$ Acesso em 03/05/2017.

OLIVEIRA, Gesner. Concorrência - Panorama no Brasil e no Mundo, São Paulo, Saraiva, 2001.

Defesa da Concorrência em Países em Desenvolvimentos: Aspectos da Experiência do Brasil e do Mercosul, 1998, Disponível em: <http://bibliotecadigital.fgv.br/dspace/bitstream/handle/10438/1863/TD66.pdf?sequen>. Acesso em: 10 nov. 2015.

Defesa da Livre Concorrência no Brasil: Tendências Recentes e Desafios à Frente, RAE - Revista de Administração de Empresas, v. 39, n. 3, São Paulo. Jul./Set. 1999. Disponível em: $<$ http://www.scielo.br/pdf/rae/v39n3/v39n3a03.pdf >. Acesso em 10 de nov. 2015. 
ORBACH, Barak. How Antitrust Lost Its Goal. In: 81 Fordham L. Rev. 2253 (2012).

ORBACH, Barak. Was the Crisis in Antitrust a Trojan Horse? Forthcoming. In: The Antitrust Law Journal (2014). Disponível em:

<http://awa2014.concurrences.com/IMG/pdf/orbach-crisis.pdf>. Acesso em 27/03/2017.

ORBACH, Barak. CAMPBELL REBLING, Grace E. The Antitrust Curse of Bigness (May 17, 2012). 85 Southern California Law Review 605 (2012); Arizona Legal Studies Discussion Paper No. 11-23. Disponível em SSRN: <https://ssrn.com/abstract=1856553>. Acesso em 27/03/2017.

ORBACH, Barak. A State of Inaction: Regulatory Preferences, Rent, and Income Inequality. Theoretical Inquiries in Law, 16(1), pp. 45-68. 2015 Retrieved 16 Jun. 2017, from doi:10.1515/til-2015-004

ORWELL, George. 1984. São Paulo: Companhia das Letras, $1^{a}$ ed. 2009.

PALARES, LLuis Cases. Derecho Administrativo de la Defensa de la Competencia. Madrid: Marcial Pons, 1995.

PALMA, JULIANA BONACORSI DE. Sanção e Acordo na Administração Pública. Malheiros Editores. 2015.

PAMPLONA, João Batista; CACCIAMALI, Maria Cristina. O Paradoxo da Abundância: recursos naturais e desenvolvimento da América Latina. In: Estudos Avançados IEA/USP, V. 31, no. 89, Janeiro/Abril: 251-271, 2017.

PENTEADO, Luciano de Camargo. Abuso do Poder Econômico-Contratual e Boa-Fé. Revista de Direito Privado, São Paulo, v. 11, p. 138-153, 2002.

PERES, Wilson. A Dimensão Local das Políticas de Competitividade Industrial. In: GUIMARÃES, Nadya Araújo e MARTIN, Scorr (orgs.). Competitividade e desenvolvimento. Atores e instituições locais. São Paulo: Senac.

PERITZ, Rudolph J. R. Foreword: Antitrust as Public Interest Law. p. 789-790. New York Law School Review, v. 35, no. 4, 1990.

PERITZ, Rudolph J. R. Toward a Dynamic Antitrust Analysis, p. 47 N.Y.L.S. L. Rev. 101 (2003).

PETERSEN, Niels. Antitrust Law and the Promotion fo Democracy and Economic Growth. Journal of Competition Law \& Economics vol.9 no.3 (September 2013): 593-636, 2013.

PGFN. Listas dos Maiores Devedores da União. Disponível em: $<$ http://www.fazenda.gov.br/carta-de-servicos/lista-de-servicos/procuradoria-geral-dafazenda-nacional-pgfn/lista-de-devedores>. Acesso em 15/06/2017. 
PFEIFFER, Roberto Augusto Catellanos. Defesa da Concorrência e Bem-Estar do Consumidor. Tese de Doutorado. Faculdade de Direito da USP. 2010.

PIERUCCI, Antônio Flávio. Secularização em Max Weber: Da contemporânea serventia de voltarmos a acessar aquele velho sentido. Rev. bras. Ci. Soc., São Paulo, v. 13, n. 37, p. 43-73, June 1998. Disponível em:

http://www.scielo.br/scielo.php?script=sci_arttext\&pid=S0102-

$69091998000200003 \& \operatorname{lng}=e n \& n r m=$ iso. Acesso em 13 Dec. 2017.

http://dx.doi.org/10.1590/S0102-69091998000200003.

PIGOU, Arthur Cecil. The Economics of Welfare. The Economics of Welfare, $4^{\mathrm{a}}$ ed. London: Macmillan, 1932.

PIKETTY, Thomas. O capital no século XXI. Rio de Janeiro: Intrínseca, 2014.

PIRES, Álvaro P. Sobre algumas questões epistemológicas de uma metodologia geral para as ciências sociais. In: POUPART, Jean; et all. A pesquisa qualitativa - enfoques epistemológicos e metodológicos. Rio de Janeiro: Vozes, 2008, p. 43-94.

PITOFSKY, Robert. The Political Content of Antitrust. University Of Pennsylvania Law Review, Philadelphia, Pa., U.S.A. Volume 127, no 4, April, 1979.

PLANCK, Max. Prefácio de Albert Einstein. Tradução de Murphy James. Londres: George Allen \& Unwin, Ltd, 1933.

PLATÃO. O Mito da Caverna. $1^{\text {a }}$ ed. São Paulo: Edipro, 2015.

POPPER, Karl. Textos Escolhidos /Karl Popper. Rio de Janeiro: Ed. PUC-RIO. 2010.

POSNER, Richard A. Problemas de filosofia do direito. São Paulo: Martins Fontes, 2007.

POSNER, Richard A. "Some Uses and Abuses of Economics in Law," HeinOnline, 46 University of Chicago Law Review 281 (1979). Disponível em:

http://chicagounbound.uchicago.edu/cgi/viewcontent.cgi?article=2864\&context=journal_artic les Acesso em: 19-02-2017.

POSNER, R. "Antitrust in the New Economy", In: John M. Olin Program in Law and Economics Working Paper No. 106, 2000. Disponível em:

$<$ http://chicagounbound.uchicago.edu/cgi/viewcontent.cgi?article=1057\&context=law_and_e conomics> Acesso em 24/04/2017.

POSSAS, M. L. Os conceitos de mercado relevante e de poder de mercado no âmbito da defesa da concorrência. IN: Revista do IBRAC, v.3, n.5, p.10-35, 1996.

POSSAS, M.L., FAGUNDES, J. E PONDÉ, J. (1995) "Política Antitruste: um enfoque Schumpeteriano". Anais do XXIII Encontro Nacional de Economia, ANPEC, dezembro.

POSSAS, M.L., FAGUNDES, J. E PONDÉ, J. Defesa da Concorrência e Regulação de Setores de Infraestrutura em Transição. In: Revista do IBRAC, v.8, n.8, p. 99-121, 2001. 
QUEIROZ, Pedro Aurélio Pereira da Silva, Agências Reguladoras e Defesa da

Concorrência. Revista do IBRAC, São Paulo, Ed. Singular, v.8, n $^{\circ}$ 02, maio de 2001.

. As Telecomunicações e o Desafio da Concorrência. Gazeta Mercantil, São

Paulo, agosto de 2001, Legal e Jurisprudência, p.2.

. Direito da Concorrência e Regulação dos Serviços Públicos. In: Revista de Direito Administrativo Econômico. Salvador: Instituto de Direito Público da Bahia. $\mathrm{n}^{\circ} 1$, fevereiro de 2005. Disponível em: <http:// www.fd.unl.pt/pt/wps/> Acesso em: 7 de agosto de 2016.

Entre Isonomia e Liberdade: o Princípio da Livre Concorrência como Paradigma Geral da Neutralidade no Campo Tributário. In: Direito tributário e financeiro I [Recurso eletrônico on-line] organização CONPEDI/UNICURITIBA; Coordenadores: Antônio Carlos Diniz Murta, Demetrius Nichele Macei, Octavio Campos Fischer Florianópolis: CONPEDI, p. 105-125, 2016. Disponível em: $\langle$ http://www.conpedi.org.br/publicacoes/02q8agmu/9084t7dw/Fn1z1A975E7wE4ey.pdf〉. Acesso em 02/07/2017.

Incentivos fiscais às montadoras não se justificam. In Revista Consultor Jurídico (CONJUR). 4 de jun de 2012. Disponível em http://www.conjur.com.br/2012-jun04/pedro-queiroz-incentivos-fiscais-montadoras-nao-justificam Acesso em: 7 de agosto de 2016.

Regulação concorrencial dos organismos geneticamente modificados.

Revista de Direito Público da Economia _ RDPE, Belo Horizonte, ano 3, n. 9, p. 219-236, jan./mar. 2005. Disponível em: http://www.direitodoestado.com/revista/REDAE-1FEVEREIRO-2005-PEDRO-AURELIO.pdf. Acesso em: 7 de agosto de 2016.

Verbete "Concorrência". In: ARNAUD, André-Jean e JUNQUEIRA, Eliane Botelho (orgs), Dicionário da Globalização (pp. 65-70). Direito, Ciência Política, Rio de Janeiro, Editora Lumen Juris, 2006.

RAFFAELLI, Enrico Adriano (ORG.). Antitrust Between EU Law and National Law / Antitrust Fra Diritto Nazionale e Diritto Dell'unione Europea: Xe Conference. Union des Avocats Europeens - UAE), 2013.

RAGAZZO, Carlos. Análise Econômica da Regulação: O Papel da Advocacia da Concorrência. Latin American and Caribbean Law and Economics Association (ALACDE) Annual Papers. 2007. Berkeley Program in Law and Economics, UC Berkeley. Disponível em $<$ http://works.bepress.com/carlos_ragazzo/1 1

. Preço Abusivo, Eficácia Jurídica e Análise Econômica: afinal, onde está a cabeça de bacalhau?. In: Revista do IBRAC. Vol. 19. São Paulo Ed. Revista dos Tribunais. 2011

RAWLS, John. Uma Teoria da Justiça. São Paulo: Martins Fontes. 2008. 
REUTERS. Trio Norte-Americano Ganha Nobel de Economia 2007, 15 de outubro de 2007. Disponível em <http://br.reuters.com/article/idBRN1521792320071015>. Acesso em 25/04/2017.

RHODES, R; BINDER, S. and ROCKMAN, B.A. The Oxford Handbook of Political Institutions. Oxford: Oxford University, 2006. Disponível em <http://cnqzu.com/library/To\%20Organize/Books/Rhodes\%20et\%20al\%20(eds)\%20$\% 20$ Handbook\%20of\%20Political\%20Institutions.pdf>. Acesso em 10 de nov. 2015.

RODAS. João Grandino. A Uber, Minimamente Regulamentado, Favorece a Livre Concorrência. In: Revista Consultor Jurídico. 15 de outubro de 2015. Disponível em: $<$ http://www.conjur.com.br/2015-out-15/olhar-economico-uber-minimamenteregulamentado-favorece-livre-concorrencia>. Acesso em: 7 de julho de 2017.

. A Colaboração Universal em Matéria Concorrencial é Digna de Nota. 8 de outubro de 2015. Disponível em: <http://www.conjur.com.br/2015-out-08/olhar-economicocolaboracao-universal-materia-concorrencial-digna-nota>. Acesso em: 5 de maio de 2016.

. A preocupação com a concorrência surgiu no direito interno. In: Revista Consultor Jurídico. 15 de outubro de 2015 (2015b). Disponível em:

$<$ http://www.conjur.com.br/2015-set-17/olhar-economico-preocupacao-concorrencia-surgiudireito-interno>. Acesso em: 5 de maio de 2016.

RODRIGUEZ, José Rodrigo. As Figuras da Perversão do Direito: Para Um Modelo Crítico de Pesquisa Jurídica Empírica Revista Prolegómenos - Derechos y Valores - pp. 99-124, 2015, II.

. PÜSCHEL, Flávia Portella. MACHADO, Marta Rodriguez de Assis.

Dogmática é conflito: a racionalidade jurídica entre sistema e problema. Série Direito em Debate - Direito Desenvolvimento Justiça. Direito GV. São Paulo: Editora Saraiva, 2012.

RODRIGUEZ, A. E. MENON, A. The Limits of Competition Policy: The Shortcomings of Antitrust in Developing and Reforming Economies (International Competition Law Series). Kluwer Law International, 2010.

RODRIK, Dani. Democracy and Economic Performance (Dezembro, 1997). Disponível em: 〈http://ksghome.harvard.edu/ drodrik/demoecon.PDF>. Acesso em: 30 junho 2015.

ROSS, Alf. Direito e Justiça. 2a edição, São Paulo: Editora: Edipro. 2007.

ROVELLI, Carlo. A Realidade não é o que Parece. A Estrutura Elementar das Coisas. Rio de Janeiro: Editora Objetiva, $1^{a}$ ed., 2017.

SACRISTÁN, José Gimeno (Org.). O que significa o currículo? In: Saberes e incertezas sobre o currículo. Porto Alegre: Penso, 2013.p.16 a 35.

SALAMA, Bruno Meyerhof. Estado de Direito e os Desafios do Desenvolvimento.

VIEIRA, Oscar Vilhena (Org.); DIMOULIS, Dimitri (Org.) São Paulo: Saraiva, 2011, pp. 4445. 
O que é Pesquisa em Direito e Economia? Caderno Direito GV No. 22 (mar/2008). Disponível em <https://works.bepress.com/bruno_meyerhof_salama/19/>. Acesso em 21/11/2015.

. Sete Enigmas do Desenvolvimento em Douglass North. Economic Analysis

of Law Review, vol. 2, no 2 (2011).

SALAMA, Bruno Meyerhof. A História do Declínio e Queda do Eficientismo na Obra de Richard Posner. In: LIMA, Maria Lúcia L. M. Pádua (org.). Trinta Anos de Brasil: Diálogos entre Direito e Economia. São Paulo: Saraiva, 2012. Republicado: Revista do Instituto do Direito Brasileiro da Faculdade de Direito da Universidade de Lisboa (RIDB), n. 1, 2012. Disponível em:<https://works.bepress.com/bruno_meyerhof_salama/35/>. Acesso em 01/03/2017.

SALOMÃO FILHO, Calixto. Direito Concorrencial - As Estruturas, São Paulo, Malheiros Editores, 1998.

Direito Concorrencial, São Paulo, Malheiros Editores, 2013.

Regulação da Atividade Econômica (princípios e fundamentos jurídicos), São Paulo, Malheiros Editores, 2001.

Teoria Crítico-estruturalista do Direito Comercial. São Paulo: Marcial Pons, 2015.

SANTACRUZ, Ruy. Preço Abusivo e Cabeça de Bacalhau. In Revista do IBRAC, v. 5, no 2. 1998.

SANTOS, Boaventura de Sousa. A Crítica da Razão Indolente: Contra o Desperdício da Experiência. São Paulo: Editora Cortez, 7ª Ed., 2000.

SAAD, Andreia. Preços excessivos 'puros' na nova Lei Antitruste: uma proposta de abordagem baseada na advocacia da concorrência" In: Revista do IBRAC: RIBRAC, v. 19, n. 22, p. 249-275, São Paulo: Revista dos Tribunais jul./dez. 2012.

SANTOS, Boaventura de Souza e CHAUÍ, Marilena. Direitos Humanos, Democracia e Desenvolvimento. São Paulo. Editora Cortez, 2013.

SHAPIRO, Ian. Os Fundamentos Morais da Política, 2006. Martins Fontes.

SCHERER, F. M.; ROSS, David. Industrial Market Structure and Economic Performance. New York: Houghton Mifflin Company. 3a . ed., 1990.

SCHMALENSEE, Richard. Antitrust Issues in Schumpeterian Industries. American Economic Review,90(2): 192-196. 2000.

SCHNEIDER, B. R. Hierarchical Capitalism in Latin America. Business, Labor, and the Challenges of Equitable Development. Chapter 7 - Business-Group Politics: Institutional Bias and Business Preferences. Cambridge University Press, 2013, pp. 139-159. 
SCHRÖDINGER. Erwin. The Present Situation in Quantum Mechanics: A Translation of Schrödinger's 'Cat Paradox' Paper. by John D. Trimmer, Proceedings of the American Philosophical Society 124:5 (Oct. 10, 1980), 323-338, 328. Disponível em: <http://www.mathematik.uni-muenchen.de/ schlenga/SS16/Material/SchroedingerEN.pdf>. Acesso em 23/03/2017.

SCHUARTZ, Luis Fernando. Inovações e Defesa da Concorrência: em busca de uma política que minimize os custos de decisões equivocadas". In: Propriedade Intelectual, Antistruste e Desenvolvimento. 35-58. TIMM, Luciano Benetti; PARANAGUÀ, Pedro (Organizadores). Rio de Janeiro: Editora FGV/Direito Rio. 2009

SCHUMPETER, J. A. Teoria do desenvolvimento econômico. São Paulo: Nova Cultura, 1997.

SERRA, Albert. La gestión transversal. Expectativas y resultados. In: Revista del CLAD Reforma y Democracia, n. 32. Jun. 2005. Caracas, Venezuela.

SHLEIFER, Andrei. 1985. A Theory of Yardstick Competition. IN: Rand Journal of Economics 16 (3): 319-327. Disponível em:

$<$ http://scholar.harvard.edu/files/shleifer/files/theory_yardstick_comp.pdf >. Acesso em: 03/04/2017.

SILVA, T. D. Gestão da transversalidade em políticas públicas. In: ENCONTRO DA ASSOCIAÇÃO NACIONAL DE PÓS-GRADUAÇÃO EM ADMINISTRAÇÃO, 35. Anais. Rio de Janeiro: ENANPAD, set. 2011.

SOKOL, D. Daniel. Antitrust, Institutions, and Merger Control (June 16, 2010). George Mason Law Review, Vol. 17, No. 4, 2010. Disponível em SSRN:

$<$ https://ssrn.com/abstract=1625965>. Acesso em 16/06/2016.

STATE OF THE UNION HISTORY. 1902 Theodore Roosevelt - TRUSTBUSTER. 13 de agosto de 2015. Disponível em: <http://www.stateoftheunionhistory.com/2015/08/1902theodore-roosevelt-trustbuster.html $>2017$. Acesso em 16/06/2016.

STEINER, G. Business, Government, and Society. 11th Ed. New York: McGraw-Hill, 2006. $731 \mathrm{p}$.

STIGLITZ, Joseph. The Price of Inequality. New York-London: W. W. Norton \& Company, 2013.

STREECK, Wolfgang. Como crises do capitalismo democrático. Novos estud. CEBRAP, São Paulo, n. 92, p. 35-56, março de 2012. Disponível em: < http://dx.doi.org/10.1590/S0101$33002012000100004>$. Acesso em 30 de maio de 2017.

STUCKE, Maurice E. Should Competition Policy Promete Happiness?81 Fordham L. Rev. 2575 (2013).

STUCKE, Maurice. Is Competition Always Good? In: E. J Antitrust Enforcement (2013) 1 (1): 162-197. DOI: <https://doi.org/10.1093/jaenfo/jns008> Published: 04 February 2013. 
TAYLOR, Charles. As Fontes do Self. A Construção da Identidade Moderna. São Paulo. Edições Loyola. 2011.

TELLES JÚNIOR, Goffredo. Direito quântico. 1915. 8ª Ed. Revista - São Paulo: Editora Juarez de Oliveira.

THE CHICAGO MAROON. Professors Talk Changing Chicago Economics. 17/04/2017. Disponível em: <https://www.chicagomaroon.com/article/2017/4/18/editorial-economistsuggests-changing-u-c-economic/> Acesso em 23/04/2017.

THE ECONOMIST. The University of Chicago Worries About a Lack of Competition. Edição Impressa da Business Section - "Crony capitalism" dia 12 de abril de 2017 (2017a). Disponível em: <http://www.economist.com/news/business/21720657-its-economists-usedchampion-big-firms-mood-has-shifted-university-chicago?frsc $=\mathrm{dg} \% 7 \mathrm{Ce}>$ Acesso em 18/04/2017.

THE ECONOMIST. Richard Thaler wins the Nobel prize for economic sciences. Edição Impressa da Business Section - "Free Exchange" do dia 10 de outubro de 2017 (2017b). Disponível em: < https://www.economist.com/news/business-and-finance/21730109economist-who-recognises-human-behaviour-not-always-strictly> Acesso em 10/10/2017.

THE HILL. Trump team may inject populist agenda into antitrust decisions. In: The Hill. 31/01/2017. Disponível em: <http://thehill.com/blogs/pundits-blog/finance/317091-trumpteam-may-inject-populist-agenda-into-antitrust-decisions> Acesso em 18/04/2017.

THE ROYAL SWEDISH ACADEMY OF SCIENCES (T.R.S.A.S.) Angus Deaton: Consumption, Poverty and Welfare. The Committee for the Prize in Economic Sciences in Memory of Alfred Nobel. 2015. Disponível em:

<http://www.nobelprize.org/nobel_prizes/economic-sciences/laureates/2015/advancedeconomicsciences2015.pdf >. Acesso em 10 de nov. 2015.

UNCTAD. Developing a competition advocacy model in the context of the introduction of competition policies in Latin America: study prepared for the Competition Law and Policy and Consumer Protection Section. Curiel Leidenz, Claudia - UNCTAD. 2002. Disponível em: <http://repository.un.org/handle/11176/334768>

UNCTAD. The relationship between competition and industrial policies in promoting economic development, Geneva, 7-9 July 2009. Disponível em:

<http://unctad.org/en/Docs/ciclpd3_en.pdf>. Acesso em 10 de nov. 2015.

UNCTAD. The role of competition advocacy, merger control and the effective enforcement of law in times of economic trouble. Disponível em: <http://unctad.org/en/Docs/tdrbpconf7d6_en.pdf>. Acesso em 10 de nov. 2015.

VALOR ECONÔMICO. Participação da indústria no PIB volta à década de 40, diz Ibre. 25/08/2015. Disponível em: http://www.valor.com.br/brasil/4194804/participacao-daindustria-no-pib-volta-decada-de-40-diz-ibre Acesso em 29 abr. 2017.

VARIAN, Hal R. Microeconomia: Princípios Básicos. 5ª ed, Rio de Janeiro: Campus, 2000. 
VENÂNCIO FILHO, Alberto. Abuso do Poder Econômico. In: Rev. Dir. Públ. e Ciência Politica - Rio dt Janeiro - Vol. VII. no 1 - jan./abr, 1964. Disponível em: <bibliotecadigital.fgv.br/ojs/index.php/rdpcp/article/download/59506/57874>. Acesso em 29 abr. 2017.

VERÍSSIMO, Marcos Paulo. AZEVEDO, Marcos Paulo Furquim de. CADE e o Controle Preventivo de Condutas. In: Jornal Valor Econômico. 29 de jun. 2014.

VIEGAS, Flávio. Os erros de cálculo do Cade no cartel do suco de laranja. In: JOTA. Disponível em: <https://jota.info/artigos/os-erros-de-calculo-cade-no-cartel-suco-de-laranja08122016>. Acesso em 29 jun. 2017.

VIEIRA, Oscar Vilhena (Org.); DIMOULIS, Dimitri (Org.). Estado de Direito e os Desafios do Desenvolvimento. São Paulo: Saraiva, 2011.

VIGOTSKI, Lev Semenovich. A Construção do Pensamento e da Linguagem. São Paulo. Ed. Martins Fontes, 2001.

VISCUSI, W. Kip; HARRINGTON Jr., Joseph E.; VERNON, J. Economics of Regulation

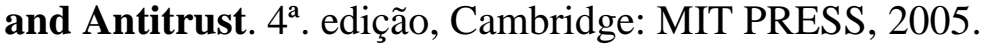

WALD, Arnoldo. O Interesse Social no Direito Privado. Publicação na RTRF3R nº 77, págs. 129/148, maio/junho - 2006.

WALLER, Spencer Weber. Corporate Governance and Competition Policy. 18 Geo. Mason L. Rev. 833 (2011).

119 (2003).

. The Uses of Business Theory in Antitrust Litigation, 47 N.Y.L.S. L. Rev.

WASHINGTON POST. Justice Department investigates beer industry anti-competition accusations. 2015. Disponível em:

$<$ https://www.washingtonpost.com/business/economy/justice-department-investigates-beerindustry-anti-competition-accusations/2015/10/12/7dc29502-712a-11e5-8248-

98e0f5a2e830_story.html?utm_term=.3c4e01b25b24>. Acesso em 19/04/2017.

WHITE HOUSE. Executive Order - Steps to Increase Competition and Better Inform, Consumers and Workers to Support Continued Growth of the American Economy, 15 de abril de 2016. Disponível em: <https://obamawhitehouse.archives.gov/the-press-

office/2016/04/15/executive-order-steps-increase-competition-and-better-inform-consumers> Acesso em 01/05/2017.

WILLIAMSON, Oliver E. Markets and Hierarchies: Analysis and Antitrust Implications. New York: Free Press, 1975.

WILLIAMSON, Oliver E. Williamson, Oliver E. Review of The Antitrust Paradox: A Policy at War with Itself by Robert H. Bork. University of Chicago Law Review: Vol. 46: Iss. 2. 1979. Disponível em:

<http://chicagounbound.uchicago.edu/cgi/viewcontent.cgi?article $=4174 \&$ context=uclrev $>$ Acesso em 19/04/2017. 
WU, Tim. In the Grip of the New Monopolists. In: The Wall Street Journal, 2010. Disponível

YOGANANDA, Paramahansa. Autobiografia de um Iogue. Editora: Self Realization Fellowship. $3^{\text {a }}$. ed., 2016

ZEPPELINI, Márcio. Advocacy: o lobby do bem. 2010. IPEA - Instituto de Pesquisa Econômica Aplicada. <http://www.ipea.gov.br/acaosocial/article26c3.html?id.article=592> Acesso em 19/04/2017.

ZIMMER, Daniel. The Goals of Competition Law. Cheltenham, UK • Northampton, MA, USA: Edward Elgar Publishing Limited, 2012.

ZOGHBI, Valentina. Strategic Priorities of Competition and Regulatory Agencies. In Developing Countries. In Politics Triumphs Economics?. Political Economy and the Implementation of Competition Law and Economic Regulation in Developing Countries. Pradeep S. Mehta (Editor). Simon J. Evenett (Editor). Academic Foundation, 2009.

ZYWICKI, Todd J., COOPER, James C. and PAUTLER, Paul A., Theory and Practice of Competition Advocacy at the FTC. Antitrust Law Journal, Vol. 72, No. 3, pp. 1091-1112, 2005; George Mason Law \& Economics Research Paper No. 04-48. Available at SSRN: $<$ https://ssrn.com/abstract=610586 or http://dx.doi.org/10.2139/ssrn.610586> Acesso em 19/04/2017. 